\title{
Real-Time Datasets Really Do Make a Difference: Definitional Change, Data Release, and Forecasting*
}

\author{
Andres Fernandez ${ }^{1}$ and Norman R. Swanson ${ }^{2}$ \\ ${ }^{1,2}$ Rutgers University, ${ }^{1}$ Universidad de Los Andes, and the ${ }^{2}$ Federal Reserve Bank of \\ Philadelphia
}

January 2009

revised: October 2009

\begin{abstract}
In this paper, we empirically assess the extent to which early release inefficiency and definitional change affect prediction precision. In particular, we carry out a series of ex-ante prediction experiments in order to examine: the marginal predictive content of the revision process, the trade-offs associated with predicting different releases of a variable, the importance of particular forms of definitional change which we call "definitional breaks", and the rationality of early releases of economic variables. An important feature of our rationality tests is that they are based solely on the examination of ex-ante predictions, rather than being based on in-sample regression analysis, as are many tests in the extant literature. Our findings point to the importance of making real-time datasets available to forecasters, as the revision process has marginal predictive content, and because predictive accuracy increases when multiple releases of data are used when specifying and estimating prediction models. We also present new evidence that early releases of money are rational, whereas prices and output are irrational. Moreover, we find that regardless of which release of our price variable one specifies as the "target" variable to be predicted, using only "first release" data in model estimation and prediction construction yields mean square forecast error (MSFE) "best" predictions. On the other hand, models estimated and implemented using "latest available release" data are MSFE-best for predicting all releases of money. We argue that these contradictory finding are due to the relevance of definitional breaks in the data generating processes of the variables that we examine. In an empirical analysis, we examine the real-time predictive content of money for income, and we find that vector autoregressions with money do not perform significantly worse than autoregressions, when predicting output during the last 20 years.
\end{abstract}

Keywords: bias; efficiency; generically comprehensive tests; rationality; preliminary, final, and real-time data. JEL classification: C32, C53, E01, E37, E47.

*Andres Fernandez, Department of Economics, Rutgers University, 75 Hamilton Street, New Brunswick, NJ 08901, USA, afernandez@fas-econ.rutgers.edu; and Department of Economics, Universidad de Los Andes, Cra. 1 No. 18A-10 Edificio C. Bogota, Colombia. Norman R. Swanson, Department of Economics, Rutgers University, 75 Hamilton Street, New Brunswick, NJ 08901, USA, nswanson@econ.rutgers.edu. The authors thank Nii Ayi Armah, Jörg Breitung, Valentina Corradi, Dick van Dijk, Philip Hans Franses, Thomas Gilbert, Jan-Egbert Sturm, Jonathan Wright, and participants at the following conferences for their many useful comments: Forecasting and Monetary Policy at the Deautsche Bundesbank, 2009 and Recent Developments in Macroeconomic and Financial Forecasting, Rotterdam, 2009. Swanson acknowledges financial support from a Rutgers University Research Council grant. The views expressed in this paper are solely our own, and do not necessarily reflect the official positions or policies of the Federal Reserve Bank of Philadelphia or the Federal Reserve System. This paper is available free of charge at www.philadelphiafed.org/research-and-data/working-papers/. 


\section{Introduction}

In an interesting paper, Aruoba (2008) finds that for most U.S. macroeconomic series, revision errors have a positive bias and are highly predictable. These finding are based on the use of information available at the time of first release. In Aruoba, Diebold, and Scotti (2008), the findings of Aruoba (2008) are used as one of the main motivating factors for the construction of a real-time business conditions measurement index. In summary, both of these papers suggest that there is much to be gained by using multiple vintages of data in the construction of predictions and prediction models. For example, one might fruitfully choose to estimate prediction models that employ all vintages (releases) of available variables, say using the Kalman filter or some other filtering procedure (see, e.g., Mariano and Tanizaki (1995)). However, modelling approaches of this variety do not explicitly account for definitional changes that characterize many U.S. series. Indeed, an important property of real-time datasets is the possibility that observations may vary across vintages for reasons other than because of "pure" revisions. Moreover, the literature has little to say concerning which release of data to predict, and whether it is preferable to use mixed releases of data when forming predictions and prediction models (as is done when "latest available release" data are used). In this paper, we attempt to shed new light on the above issues. Key precedents to our research on the informational content of real-time datasets include: Diebold and Rudebusch (1991), Hamilton and Perez-Quiros (1996), Bernanke and Boivin (2003), and the papers cited therein.

Our approach is to construct a variety of different real-time prediction models and to evaluate their performance in a series of ex-ante prediction experiments that are designed to mimic forecasting approaches used when constructing forecasts in real-time, for the purpose of policy setting and generic real-time decision making. Our prediction models include, among others, one that uses only first release data and one that utilizes the only latest available data (i.e., uses a mixture of most recent first release data and more distant later release data). Some of our models include revision errors as regressors, hence allowing us to examine the marginal predictive content of the revision process. In addition, our experiments are designed to find out whether it matters which

release of data one chooses to forecast, which release(s) of data should be used when estimating prediction models, and how definitional change in real-time variables affects our findings regarding which release of data to predict. Finally, our experiments are used to form simple rationality tests that are based solely on the examination of ex-ante predictions, rather than being based on in-sample regression analysis, as are many tests in the extant literature (see Corradi, Fernandez, 
and Swanson (2009) for further discussion).

The results of our prediction experiments point clearly to the need for making real-time datasets available to empirical researchers. In almost all cases that we consider, multiple releases of a variable are useful for constructing MSFE-best predictions. We also find new evidence that early releases of money are rational, whereas prices and output are irrational. More important, we present evidence concerning whether or not one should aim to predict the "first release" or "final" release of a variable, and which data are most useful for model estimation and prediction construction. We find that regardless of which release of prices one specifies as the "target" variable to be predicted, using only "first release" data in model estimation and prediction construction yields MSFE-best predictions. On the other hand, models estimated and implemented using "latest available release" data are MSFE-best for predicting all releases of money. Thus, perhaps surprisingly, in our empirical analysis we find that the choice of which release of data to predict seems not to have an impact on which releases of data should be used in estimation and prediction construction. However, differences in how to utilize real-time datasets do arise when the variable being modelled and predicted changes.

One of the reasons for the difference in our findings for money and prices is the presence of definitional change (or "definitional breaks") in the money variable. By definitional break, we mean the following. Assume that a variable is re-defined at some point in time, say $t_{0}$. Then, calendar dated observations prior to time period $t_{0}$ are generated according to the earlier variable definition and earlier data generating process (DGP) when the vintages associated with the observations are prior to $t_{0}$. However, when the vintages being examined are after period $t_{0}$, then DGP associated with the same calendar dated observations is different (i.e., it is the "post break" DGP). In the context of real-time data, a definitional break naturally results in later vintages of data for particular calendar dates being generated from a different DGP. Definitional breaks thus result in the "contamination" of any time series of observations constructed using only early releases of a variable, hence resulting in poor parameter estimates in models that use only early release data. In effect, if definitional breaks are too substantial, then use of early release data is tantamount to forming time series by concatenating data from various different DGPs. ${ }^{1}$ These definitional break problems do not appear to be an issue for prices. Indeed, in the case of prices, any definitional break problems are outweighed by problems associated with estimating models and forming predictions using mixed vintages of data, given that estimating models using only first release data yield MSFE-best predictions, regardless of which release is being predicted (i.e., regardless of which

\footnotetext{
${ }^{1}$ In the sequel, we use the terms "definitional change" and "definitional breaks" interchangably, to underscore the fact that they are the same in the context of our analysis.
} 
release is the "target" variable). In summary, for prices, using early releases of data yields MSFEbest predictions, regardless of definitional breaks. On the other hand, for money, the impact of definitional breaks is serious enough to warrant using only latest release data for prediction and model construction.

In addition to the above findings, note that although early release data are MSFE-best for predicting prices, our price variable is the only one for which we find clear evidence pointing to the importance of the revision process for ex-ante prediction as the inclusion of revision errors enhances the forecasting performance of the models considered. This apparently contradictory evidence points to a trade-off between using irrational early release data versus using mixtures of different releases of data when specifying and estimating prediction models and should be taken as evidence that prices are actually "mildly irrational", which agrees with earlier findings in the literature, such as those discussed in Corradi, Fernandez, and Swanson (2009). In summary, the inefficiency of early release prices in our analysis is outweighed by the confounding nature of using mixed releases of data when estimating our prediction model, thus leading to our finding that using only "first available" data in model estimation and prediction construction yields MSFE-best predictions, regardless of which release of prices is taken to be the "target" variable to be predicted. With respect to money and output, we find there is little information in their revision processes. ${ }^{2}$

In order to illustrate the implementation of our experimental setup, we carry out an empirical analysis in which we examine the real-time predictive content of money for income, building on the work of Stock and Watson (1989), Amato and Swanson (2001), Garratt, Koop, Mise, and Vahey (2009), and others. While we find little marginal predictive content in money, we note that vector autoregressions with money do not perform significantly worse than autoregressions, when predicting output in the past 20 years. Put differently, although the addition of money does not add marginal predictive content to our models, the predictive performance is not worsened. This is somewhat surprising because models with irrelevant variables should be less efficiently estimated, leading in many cases to worsened predictive performance.

The rest of the paper is organized as follows. In Section 2, we outline some notation, and in Section 3, we discuss the empirical methodology used in the remainder of the paper. In particular, we outline the variety of real-time prediction models that we analyze, and we discuss our approach to testing for rationality. Section 4 contains a discussion of the data used, as well as our empirical

\footnotetext{
${ }^{2}$ In addition to presenting evidence of the impact of definitional breaks on our real-time money dataset, we also provide similar evidence that our output dataset is substantively impacted by definitional breaks. The reason for this is that our model which uses "latest available release" data, yields superior predictions of output, particularly when the release being predicted is a later release.
} 
findings. In Section 5, we summarize the results from our empirical illustration. Concluding remarks are given in Section 6. Tables, figures, and appendices are collected at the end of the paper.

\section{Setup}

Let ${ }_{t+k} X_{t}$ denote a variable (reported as an annualized growth rate) for which real-time data are available, where the subscript $t$ denotes the time period to which the datum pertains, and the subscript $t+k$ denotes the time period during which the datum becomes available. In this setup, if we assume a one-month reporting lag, then first release or "preliminary" data are denoted by ${ }_{t+1} X_{t}$. In addition, we denote fully revised or "final" data, which is obtained as $k \rightarrow \infty$, by ${ }_{f} X_{t}$. Data are grouped into releases and vintages. The first release is preliminary data, the second release is $2^{\text {nd }}$ available data, and so on. In regard to vintages, the 2000:1 vintage is the time series of latest release data available in 2000:1, and the 2000:2 vintage is the time series of latest release data available in 2000:2, and so on. Regression models parameterized using the latest available release of data at each point in time use the most recently available vintage. Such models correspond to those usually used in practice. Regression models parameterized using only a single release of data use time series constructed by taking a single observation from each vintage of data.

To further set notation, let ${ }_{t+2} u_{t}^{t+1}={ }_{t+2} X_{t}-_{t+1} X_{t}$, and ${ }_{t+1} V_{t}=\left({ }_{t+1} X_{t}, t_{t+1} u_{t-1}^{t}\right)$, where ${ }_{t+1} u_{t-1}^{t}={ }_{t+1} X_{t-1}-{ }_{t} X_{t-1}$. Thus, ${ }_{t+2} u_{t}^{t+1}$ and ${ }_{t+1} u_{t-1}^{t}$ denote the errors between the second and the first releases at time $t+2$ and at time $t+1$, respectively. Furthermore, let $\mathcal{F}_{t}^{t+1}=$ $\sigma\left({ }_{s+1} V_{s} ; 1 \leq s \leq t\right)$, so that $\mathcal{F}_{t}^{t+1}$ contains information available at the time of the first release, assuming a one month lag before the first datum becomes available.

\section{Empirical Methodology}

\subsection{Prediction}

In this subsection, we discuss the prediction models that will be used for addressing the questions outlined above. In particular, we consider the issue of prediction using various variable/vintage combinations as defined in the following set of models.

Model A (First Available Data): ${ }_{t+k} X_{t+1}=\alpha_{t+1, t}^{A}+\sum_{i=1}^{p^{A}} \beta_{i, t+1, t}^{A} t+2-i X_{t+1-i}+{ }_{t+k} \epsilon_{t+1}^{A}$;

Model B ( $k^{\text {th }}$ Available Data) ${ }_{t+k} X_{t+1}=\alpha_{t+1, t}^{B}+\sum_{i=1}^{p^{B}} \beta_{i, t+1, t}^{B}{ }_{t+2-i} X_{t+3-k-i}+_{t+k} \epsilon_{t+1}^{B}$;

Model C (Latest Available Data): ${ }_{t+k} X_{t+1}=\alpha_{t+1, t}^{C}+\sum_{i=1}^{p^{C}} \beta_{i, t+1, t}^{C}{ }_{t+1} X_{t+1-i}+{ }_{t+k} \epsilon_{t+1}^{C}$.

In the above models, the time subscripts on the model coefficients are meant to indicate that the parameters are estimated using particular calendar and release dated observations from our 
real-time datasets and correspond to the final calendar date and release combination in the dataset used to estimate the models. Our analysis is carried out by recursively estimating the above models and subsequently constructing sequences of ex-ante 1-step ahead predictions, for various values of $k$. Notice that when $k=2$, we are assuming that the "target variable" to be forecast is the first release.

Model A has explanatory variables that are formed using only first available data. Thus, the first model corresponds to the approach of simply using first available data and ignoring all later releases, regardless of which release of data is being forecasted. As discussed above, this model should be expected to perform well if data revisions are "news" and if definitional changes do not contaminate the data. If definitional changes affect our data, then one might expect that Model A would perform well for very small values of $k$, but would perform increasingly worse as $k$ increases.

Model B is specified using explanatory variables that are available $k-1$ months ahead, corresponding to $(k-1)^{s t}$ available data. Thus, this model uses data that have been revised $k-1$ times in order to predict data that likewise have been revised $k-1$ times. In this sense, Model B is included only as a "reality check", as the model uses stale information in all instances other than the case in which $k=2$ (in which case Models $\mathrm{A}$ and $\mathrm{B}$ are equivalent). However, when $k>2$, the calendar date of information used to predict one-step ahead is at least two periods prior to the prediction period. Therefore, the "cost" of using Model B is the inclusion of "stale" data, and hence the model should be expected to perform poorly.

In Model C, the latest release of each observation is used in prediction, so that the dataset is fully updated prior to each new prediction being made. We refer to this model as our "latest available data" model because policy makers and others who construct new predictions each period, after updating their datasets and re-estimating their models, generally use this type of model. If useful information accrues via the revision process, then one might expect that using latest available data (Model C) would yield a better predictor of ${ }_{t+k} X_{t}$ than when only "stale" first release data are used (Model A), for example. Of course, the last statement has a caveat. Namely, it is possible that first release data are best predicted using only first release regressors, second release using second release regressors, etc. This might arise if the use of real-time data as in Model $\mathrm{C}$ results in an "informational mix-up" due to the fact that every observation used to estimate the model is a different release, and only one of these releases corresponds to the release being predicted, at any point in time (see discussion in Section 1 for further details). However, Model C is not subject to the sort of definitional break problems that may plague Models A and B. Because of this fact, 
it is of interest to assess whether the "cost" of using models which incorporate definitional breaks is greater than the "cost" of using mixed release datasets, when predicting a single release, $k$. We are thus interested in finding out whether Model C "wins" or not, because it will tell us whether using latest release data that avoids definitional break issues offsets the "mixture of releases" issues associated with the use of Model C. For example, if first release data are "best" predicted using our "latest release data" model, then one should conclude that definitional changes are important, and that real-time datasets that include many vintages of data, such as that used by Mariano and Tanizaki (1995), have definitional change problems that have not been addressed in the literature, thus far. For further discussion of real-time forecasting using models such as Model C, the reader is referred to Swanson and van Dijk (2006) and Faust and Wright (2009).

It is important to note that the models given above cannot be directly implemented in practice in order to construct real-time predictions. The reason for this can be illustrated easily by examining Model C. Say that the intercept is zero, $p=1$ and $k=3$. Then, the natural least squares estimator is:

$$
\widehat{\beta}_{1, t+k-1, t}=\frac{\sum_{j=2}^{t}{ }_{t+k-1} X_{j t} X_{j-1}}{\sum_{j=2}^{t}{ }_{t} X_{j-1}^{2}} .
$$

Here, predictions would then be calculated using ${ }_{t+k} \widehat{X}_{t+1}^{f}=\widehat{\beta}_{t+k-1, t \quad t+1} X_{t}$. The problem with this formulation is that while $\widehat{\beta}_{t+k-1, t}$ uses data that are calendar dated $t$ or earlier, the vintage of data used in the estimator when $j=t$ is $t+2$, which is available only in calendar period $t+2$. On one hand, this approach is sensible, given that we are interested in predicting the second release of data at calendar date $t+1$. On the other hand, this approach is not sensible, because we would be using future information to predict the past (i.e., the future information appears in $\widehat{\beta}_{t+k-1, t}$ ). In order to carry out true real-time prediction, we must assume that we have observations for calendar dates only up until period $t$, using only vintages $t+1$ and earlier. For this reason, implementation of the models in practice requires that the models be estimated only for $k=2$, and that these estimators be used for predictions for all data releases. ${ }^{3}$ The key insight necessary in order to understand the above argument is that real-time prediction involves using both calendar and release dated information available up until the period just prior to the prediction period, when forming 1-step ahead forecasts. This in turn implies that one generally uses first release data, at least for the most recently available calendar dated observation. However, if one constructs estimators such as $\widehat{\beta}_{1, t+k-1, t}$, then in order to ensure that the prediction is real-time, one must use data only up until

\footnotetext{
${ }^{3}$ Alternatively, predictors could be calculated using calendar dated observations ending $k-2$ periods prior to the most recently available calendar observation. This latter approach is clearly sub-optimal (except for the case in which $k=2$ ), given the importance of the first order autoregressive coefficients in our models and in prediction models in general, and hence is not implemented.
} 
$k-2$ periods prior to the most recently available calendar observation. As expected, experiments that we carried out suggest that this approach leads to poorer predictions - it is better to use early releases on recent calendar dates than only later releases, hence precluding the use of the most recent calendar dated observations.

Given the above considerations, one natural approach is to compare the following prediction equations (least squares estimators for the intercept and first order slope parameter in each model are also given):

Model A Prediction Equation: ${ }_{t+k} \widehat{X}_{t+1}^{f}=\widehat{\alpha}_{t+1, t}^{A}+\sum_{i=1}^{p^{A}} \widehat{\beta}_{i, t+1, t}^{A} t+2-i X_{t+1-i}, \quad$ for $t=R, \ldots, T-k$, where

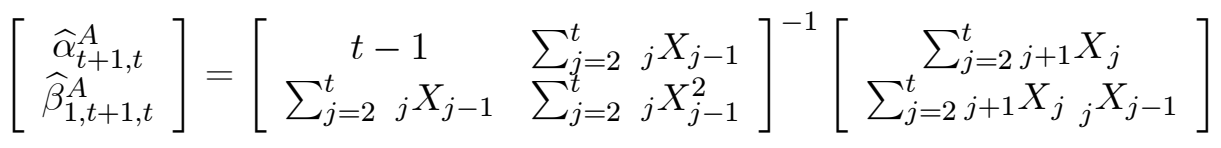

Model B Prediction Equation: ${ }_{t+k} \widehat{X}_{t+1}^{f}=\widehat{\alpha}_{t+1, t}^{B}+\sum_{i=1}^{p^{B}} \widehat{\beta}_{i, t+t+k-i}^{B} X_{t+1-i}, \quad$ for $t=R, \ldots, T-k$, where

$$
\left[\begin{array}{c}
\widehat{\alpha}_{t+1, t}^{B} \\
\widehat{\beta}_{1, t+1, t}^{B}
\end{array}\right]=\left[\begin{array}{ccc}
t-1 & \sum_{j=2}^{t}{ }_{j} X_{j+1-k} \\
\sum_{j=2}^{t}{ }_{j} X_{j+1-k} & \sum_{j=2}^{t} & j X_{j+1-k}^{2}
\end{array}\right]^{-1}\left[\begin{array}{c}
\sum_{j=2 j+1}^{t} X_{j+2-k} \\
\sum_{j=2}^{t}{ }_{j+1} X_{j+2-k} X_{j+1-k}
\end{array}\right]
$$

Model C Prediction Equation: ${ }_{t+k} \widehat{X}_{t+1}^{f}=\widehat{\alpha}_{t+1, t}^{C}+\sum_{i=1}^{p^{C}} \widehat{\beta}_{i, t}^{C}{ }_{t+1} X_{t+1-i}, \quad$ for $t=R, \ldots, T-k$, where

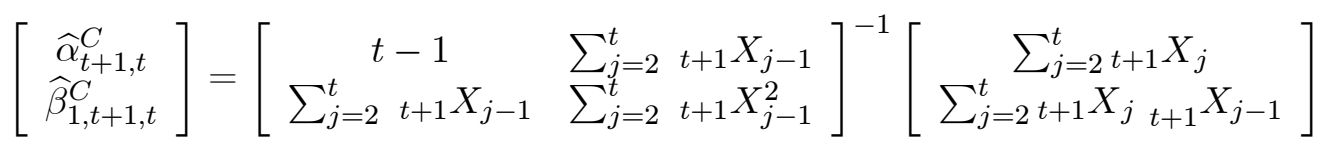

Notice that the estimators used in the three prediction models are indeed quite different. Moreover, analogous least squares estimators for all other parameters in the prediction equations follow immediately (by simply setting $k=2$ in the original models). Given the above formulation, it is also clear that the straw-man random walk with drift prediction model that we also consider in our experiments has intercept parameter that differs across the three models.

In our prediction experiments, we set: (i) $p=1$; (ii) $p=S I C$; (iii) $p=A I C$; (iv) $p=0$ (random walk with drift model). ${ }^{4}$ Additionally, we set $k=\{2,3,4,6,12,24\}$. Furthermore, in addition to the basic regression model, we consider models in which we include additional revision error regressors of the form: ${ }_{t+1} W_{t}^{\prime}={ }_{t+1} u_{t-1}^{t}, t_{t+1} W_{t}^{\prime}=\left({ }_{t+1} u_{t-1}^{t},{ }_{t} u_{t-2}^{t-1}\right), t_{t+1} W_{t}^{\prime}={ }_{t+1} u_{t-2}^{t-1}$, and ${ }_{t+1} W_{t}^{\prime}=\left({ }_{t+1} u_{t-1}^{t}, t_{+1} u_{t-2}^{t}\right)$, where the notation used in these regressors is defined at the end of the previous section.

\footnotetext{
${ }^{4}$ Models with lags selected using the Schwarz Information Criterion (SIC) yielded more accurate predictions, on average; therefore we do not report findings for cases (i) and (iii). Complete results have been tabulated, though, and are available on request from the authors.
} 
All experiments are based on the examination of the MSFEs associated with 1-step ahead predictions constructed using recursively estimated models, where $R$ observations are used in our first estimation, $R+1$ observations are used in our second estimation, etc. We thus construct sequences of $P-k$ ex-ante predictions and prediction errors, where $T=R+P$ is the sample size. We set $R$ to be 1969:4, so that our first prediction is calendar date 1970:1. The start calendar date of our dataset is 1959:4, and we have vintages of data from 1965:4. Predictions are constructed using recursively estimated models with ex-ante prediction periods beginning in 1983:1 or 1990:1.

In an empirical example, we also estimate multivariate versions of all of the models described above, where we include: (i) money, income, prices, and interest rates; and (ii) income, prices, and interest rates. In these models, it is assumed that the target variable of interest is output growth. Thus, we are examining, in real-time, the marginal predictive content of money for output, using various data vintages, various revision errors, and for a target variable that corresponds to various releases of output growth. Other recent papers examining the usefulness of real-time data for prediction include Robertson and Tallman (1998), Gallo and Marcellino (1999), and the papers cited therein.

MSFEs are examined via the use of Diebold and Mariano (DM: 1995) and Clark and McCracken (2001) predictive accuracy test (see also Clark and McCracken (2005), Clark and McCracken (2009)). ${ }^{5}$ The test has a null hypothesis of equal predictive accuracy and is defined as follows:

$$
D M=\sqrt{P-k} \frac{\frac{1}{P} \sum_{t=R}^{T-k} \widehat{d}_{t, k}}{\frac{1}{P-k} \sum_{j=-\bar{j}}^{\bar{j}} \sum_{t=R+j}^{T-k} K\left(\frac{j}{M}\right)\left(\widehat{d}_{t}-\bar{d}\right)\left(\widehat{d}_{t-j}-\bar{d}\right)},
$$

where $\widehat{d}_{t, k}=l\left(\widehat{\varepsilon}_{1, t, k}\right)-l\left(\widehat{\varepsilon}_{2, t, k}\right)$ is a random variable defined to be the difference between the prediction errors of two models that are being compared, when transformed according to a given loss function, $l, \bar{d}=\frac{1}{P-k} \sum_{t=R}^{T-k} \widehat{d}_{t, k}$, and the denominator is a heteroskedasticity and autocorrelation consistent covariance estimator, such as the Newey-West estimator. The limiting distribution of the DM statistic is given in Theorems 3.1 and 3.2 in Clark and McCracken (2005) under quadratic loss, so that $\widehat{d}_{t, k}=\widehat{\varepsilon}_{1, t, k}^{2}-\widehat{\varepsilon}_{2, t, k}^{2}$, and is $N(0,1)$ in cases in which the prediction models are nonnested and parameter estimation error vanishes (or the in-sample and out-of-sample loss functions are the same - see also Corradi and Swanson (2006)). In the sequel, we consider only quadratic loss and

\footnotetext{
${ }^{5}$ Clark and McCracken (2009) reconsider tests for comparing nonnested as well as nested forecasting models, when forecasts are produced using real-time data. They show that, under the news hypothesis, data revisions do not affect the limiting distributions of tests for predictive evaluation. On the other hand, the use of real-time data plays a crucial role whenever revisions are noisy and effects are different, depending on whether we are comparing nonnested or nested models.
} 
hence report mean square forecast errors (MSFEs) as well as DM test statistics based on quadratic loss.

\subsection{Rationality Tests}

Perhaps the most frequently implemented rationality tests in the literature are based on the following variety of regression model:

$$
{ }_{f} X_{t}=\alpha+{ }_{t+1} X_{t} \beta+{ }_{t+1} W_{t}^{\prime} \gamma+\epsilon_{t+1}
$$

where ${ }_{t+1} W_{t}$ is an $m \times 1$ vector of variables representing the conditioning information set available at time period $t+1$ and $\epsilon_{t+1}$ is an error term assumed to be uncorrelated with ${ }_{t+1} X_{t}$ and ${ }_{t+1} W_{t}$. The null hypothesis is $H_{0}: \alpha=0, \beta=1$, and $\gamma=0$ and corresponds to the idea of testing for the rationality of ${ }_{t+1} X_{t}$ for ${ }_{f} X_{t}$, by finding out whether the conditioning information in ${ }_{t+1} W_{t}$, available to the data issuing agency at the time of first release, has been efficiently used (see Mankiw, Runkle, and Shapiro (1984), Mankiw and Shapiro (1986), Kavajecz and Collins (1995), Mork (1987), Keane and Runkle (1990), and Rathjens and Robins (1995) for further details). A summary of this sort of test is given in Swanson and van Dijk (2006). Additionally, Swanson and van Dijk (2006) consider the entire revision history for each variable and hence discuss the "timing" of data rationality by generalizing (1) as follows:

$$
{ }_{t+k} X_{t}-{ }_{t+1} X_{t}=\alpha+{ }_{t+1} X_{t} \beta+{ }_{t+1} W_{t}^{\prime} \gamma+\epsilon_{t+k},
$$

where $k=1,2, \ldots$ defines the release (or vintage) of data. Rather than carrying out regression-based tests using the above models, Corradi, Fernandez, and Swanson (CFS: 2009) consider moment-type tests that assess whether revision errors can be "explained" using contemporaneous information. The CFS test that we use in this paper is defined as follows:

$$
M_{T}=\sup _{\gamma \in \Gamma}\left|m_{1, T}(\gamma)\right|
$$

where, for example: $m_{T}(\gamma)=\frac{1}{\sqrt{T}} \sum_{t=1}^{T-2} t_{t+2} u_{t}^{t+1} w\left(\sum_{j=0}^{t-1} \gamma_{j}^{\prime} \Phi\left(t+1-j W_{t-j}\right)\right)$,

$$
\Gamma=\left\{\gamma_{j}: a_{j} \leq \gamma_{j} \leq b_{j}, j=1,2 ;\left|a_{j}\right|,\left|b_{j}\right| \leq B j^{-\kappa}, \kappa \geq 2\right\}
$$

${ }_{t+1-j} W_{t-j}$ is information available in real-time, and $\Phi$ is a so-called generically comprehensive function, allowing for the construction of a test that is consistent against generic nonlinear alternatives. In this test, the null hypothesis is $H_{0}: E\left({ }_{t+2} u_{t}^{t+1} \mid \mathcal{F}_{t}^{t+1}\right)=0$ a.s., which states that the first release is rational and unbiased, as the revision error in this case is a martingale difference sequence, 
adapted to the filtration generated by the entire history of past revision errors and past values of the variable to be predicted. This is consistent with the "news" version of rationality, according to which subsequent data revisions only take into account news that was unavailable at the time of the first release. Thus, if we fail to reject $H_{0}$, it means that the first data release already incorporates all available information at the current time and hence "improved" predictions cannot be constructed. Should $H_{0}$ be rejected, CFS outline another test for assessing whether the rejection is due to nonzero bias or inefficiency. Moreover, and as shown in Lemma 1 of de Jong, $\left(\Gamma,\left\|\gamma-\gamma^{\prime}\right\|\right)$ is

a compact metric space, with $\left\|\gamma-\gamma^{\prime}\right\|=\left(\sum_{j=1}^{\infty} j^{\kappa}\left|\gamma_{j}-\gamma^{\prime}\right|^{2}\right)^{1 / 2}$, where $|\cdot|$ denotes the Euclidean norm. In practice, one can allow for $\kappa=2$ and choose $a_{j}=a(j+1)^{-2}$ and $b_{j}=b(j+1)^{-2}$, where $a$ and $b$ belong to some compact set in $\mathcal{R}^{q}$. It can be seen immediately that the weight attached to past observations decreases over time. Indeed, as stated in the assumptions in CFS, the revision error is assumed to be a short memory process and, therefore, it is "independent" of its distant past.

In addition to the above tests, in this paper we use the simple regression-based test given in (2) in order to test rationality. Our implementation of the test involves replacing ${ }_{t+1} W_{t}^{\prime}$ in the regression with various different revision errors. However, rather than examining the values of the coefficients in the regression model in order to test for rationality, we directly use the regression model to construct sequences of ex-ante predictions. Then, the accuracy of these predictions is assessed using the DM test. This is a truly out-of-sample rationality test and is in the spirit of those suggested in Ashley, Granger, and Schmalensee (1980), Chao, Corradi, and Swanson (2001), and Corradi and Swanson (2002).

\section{Empirical Results}

\subsection{Data}

Our real-time dataset includes real GDP (seasonally adjusted), the GDP chain-weighted price index (seasonally adjusted), the money stock (measured as M1, seasonally adjusted) and the interest rate (measured as the rate on the three-month Treasury bill). All series have a quarterly frequency and our real-time dataset for each of the four variables was obtained from the Federal Reserve Bank of Philadelphia's real-time dataset for Macroeconomists (RTDSM). The RTDSM can be accessed online at http://www.phil.frb.org/econ/forecast/readow.html. The series were obtained from the "by-variable" files of the "core variables/quarterly observations/quarterly vintages" dataset, and are discussed in detail in Croushore and Stark (2001, 2003) and Croushore (2006). Note also that 
interest rates are not revised, and hence our interest rate dataset is a vector rather than a matrix (see Swanson, Ghysels and Callan (1999) and Ghysels, Swanson, and Callan (2002) for a detailed discussion of the calendar date/vintage structure of real-time datasets).

The first vintage in our sample is 1965:4, for which the first calendar observation is 1959:3. This means that the first observation in our dataset is the observation that was available to researchers in the fourth quarter of 1965, corresponding to calendar-dated data for the third quarter of 1953 . The datasets range up to the 2006:4 vintage and the corresponding 2006:3 calendar date, allowing us to keep track of the exact data that were available at each vintage for every possible calendar-dated observation up to one quarter before the vintage date. This makes it possible to trace the entire series of revisions for each observation across vintages.

Various summary information about the datasets is depicted in the first six plots in Figures 1-3. For example, note that we use log-differences throughout our analysis (except for interest rates); and various releases of the log-differences of all variables, except the interest rate, are depicted in the plots. Also included are plots of the first and second revision errors measured as the difference between the first vintage (e.g. first available) of a calendar observation and the second and third vintages, respectively, and cumulative revision errors for various releases. As can readily be seen on inspection of the distributions of the revision errors as well as via examination of the summary statistics reported in Table 1, the first revision (i.e., the difference between the first and second vintages) is fairly close to normally distributed. On the other hand, the distribution of the second revision errors is mostly concentrated near zero, implying that much of the revision process has already taken place in the first revision. Indeed, the distributional shape of revision errors beyond the first revision is very much the same as that reported for the second revision in these plots, with the exception of revision errors associated with definitional and/or other structural issues associated with the variables. This is one of the reasons why much of our analysis focuses only on the impact of first and second revision errors - later revision errors appear to offer little useful information other than signalling the presence of definitional and related structural issues associated with the variables. Indeed, as was mentioned before, an important property of real-time datasets like the RTDSM is the possibility that calendar observations may vary across vintages for reasons other than because of "pure" revisions. This feature of the data is illustrated in plots with title "Calendar data across vintages" in Figures 1-3, where we have plotted early calendar dates (e.g., 1959:1; 1962:1; and 1965:3) across all available vintages in our sample. Of note is that the data for a particular calendar date sometimes vary significantly across vintages. For instance, looking at the 1959:Q4 calendar 
observation for output across all vintages, one can observe several discrete movements driving the value of that particular observation from a monthly growth of $1 \%$ for the earlier vintages to $0.5 \%$ for the later vintages. It seems reasonable to argue that most (if not all) of the discrete variations in that particular calendar observation are not due to "pure revisions", but are solely a consequence of definitional breaks in the measurement of output. To verify this claim, we plotted and compared several other calendar observations across all vintages and we could identify nine clear breaks in the following dates: 1976:Q1; 1981:Q1; 1986:Q1; 1992:Q1, 1996:Q1, 1997:Q2; 1999:Q4; 2000:Q2; and 2004:Q1. These are the breaks that define the sample periods for which summary statistics are reported in Table 2; and inspection of this table suggests that the basic properties of the series often change after such definitional breaks. This can be graphically illustrated by noticing that for output, the three calendar dates plotted often exhibit abrupt changes in the same vintages, corresponding to these dates. Not surprisingly, the same nine breaks were identified in our measure of prices, since our measure is a composite measure of GDP prices. However, it should be noted that the same procedure for the money series does not yield such well defined definitional breaks because some of the breaks do not apply to all vintages.

In Section 1, we argued that the variable that one cares about predicting may in some cases be a near-term vintage. If one cares about final data, one may in some cases have a difficult time, as one would need then to predict unknowable future definitional and other methodological changes implicit to the data construction process. Of course, this argument can be checked by examining the performance of our prediction models. However, note that the above discussion suggests that this argument is worthy of investigation. Namely, "pure revision" appears to occur in the near-term, definitional change occurs in the long term, and little occurs between. Moreover, application of simple level shifts to datasets in order to address the definitional break issue may be inadequate in some cases because the entire dynamic structure of a series might have changed after a definitional change so that the current definition of GDP may define an entirely different time series than that based on an earlier definition, say (see introduction for further discussion). It should be noted that the summary statistics reported in Table 2 suggest that there are indeed significant differences between the means and other measures associated with series in different subsamples, at least for output. This evidence, thus, points to at least one benefit of using only the latest vintage of data in prediction, such as is done when using Model C. However, we shall see in the next section that Model $\mathrm{C}$ does not always yield the best predictions, suggesting that the definitional breaks are not always problematic to analysis of real-time data. 


\subsection{Prediction Experiments}

As discussed in Section 3, we carried out three types of autoregressive prediction experiments, in which the objective was to forecast output, prices, and money. The methods involved fitting regression Models A, B, and C. Recall that Model B is our "strawman" model, and should be expected to perform increasingly poorly as $k$ increases. Moreover, Model A involves constructing predictions using only first release data and hence might be expected to perform poorly for predicting $k^{\text {th }}$ releases, when $k$ is large, assuming that either: (i) our data are irrational, or (ii) definitional changes result in "contamination" of the earliest first release calendar-dated observations used in the construction of our prediction models. On the other hand, Model C uses a mixture of releases both in parameter estimation and in prediction construction. Thus, even if there are efficiency and/or definitional break problems associated with using first release data in Model A, these may be outweighed by the cost of using mixed releases of data in Model $\mathrm{C}$, and hence Model A might still be MSFE-best.

Turning now to our results, note that Tables 3-5 report on the predictive accuracy of Models A-C using simple autoregressive models, and Tables A1.1-A1.3 (see Appendix 1) contain the same summary statistics, except that additional regressors in the form of revision errors are added to the models (as discussed above). Entries in the tables are MSFEs and DM test statistics that are calculated with Model A as the benchmark. In Tables 1-3, entries in bold denote lowest MSFEs for a particular value of $k$, across all models. Each Table is subdivided different panels according to the date of the first prediction (either 1970:1, 1983:1, or 1990:1). All predictions are constructed using recursively estimated models. A number of clear-cut conclusions emerge when the results reported in these tables are examined.

In Table 3, the MSFE-best output predictions result when using Model A for low values of $k$, and using Model $\mathrm{C}$ for high values of $k$. However, for price predictions (see Table 4), Model A is always MSFE-best, while for money, Model C is always MSFE-best, regardless of release being predicted and data subsample (see Panels A, B, and C in Table 5). These results are consistent with a number of conclusions.

First, note that if there are no problems with the data due to definitional change, and early releases are rational, then one might expect that Model A could dominate Model C, assuming that the issue of using mixed releases of data in Model C sufficiently reduces predictive accuracy so as to make the use of Model A preferable. This is exactly the case that occurs with prices. Of course, early price releases might still be "mildly irrational", it is just that if definitional changes are not 
a big problem, then the "cost" of using mixed releases of data for parameter estimation as well as for prediction construction, when the objective is to predict a particular release, may outweigh the "costs" associated with "mild" inefficiency and/or definitional change problems. Indeed, when we inspect Tables A1.1-A1.3 we shall see that this is exactly what is occurring for prices.

Second, the fact that Model C "wins" when predicting money suggests that inefficiency and/or definitional change problems associated with early release data in Model A outweigh any potential mixed release problems associated with using Model C. This suggests that an important role for our efficiency test as well as extant efficiency tests is to distinguish between efficiency problems and definitional change problems. In particular, if efficiency tests fail to reject, while at the same time Model C is MSFE-best, regardless of release being predicted, then we have direct evidence of definitional change problems being present in the data. Again, we shall later see that this is indeed the case, as our efficiency tests all fail to reject the rationality of money.

Third, given the results discussed above, we have clear evidence that whether or not one should use the latest or earlier releases of data in model parameter estimation and prediction construction is not just dependent on the release of data to be predicted, but is also dependent on what the target variable of interest is. When the target variable is money, Model $\mathrm{C}$ is preferred (i.e., use the latest available data). However, when the target variable is prices, Model A is preferred. Most importantly, precisely which model is preferred is independent of the release, $k$, being predicted, for both prices and money. This suggests that the "target release" to be predicted is actually not very important for these variables, which is quite surprising. The reason why this finding is surprising is that one might expect the cumulative effect that the combination of inefficiency, measurement error, and definitional change has on model choice will result in different models being chosen when the target release to be predicted increases from preliminary to final data, as is the case with output.

In summary, these first results constitute strong evidence that real-time datasets are indeed useful. Failure to use real-time datasets will result in sub-optimal predictions, when the objective is to minimize MSFEs.

As mentioned above, for output, Model A "wins" when predicting early releases, while Model C "wins" when predicting later releases. This suggests that there is either sufficiently substantive measurement error or there is sufficient inefficiency that for predicting later releases, prediction models estimated using only first release data are not useful. However, the use of mixed releases of data in estimation of Model $\mathrm{C}$ is sufficiently costly that predicting early releases is best done with Model A. 
As expected, Model B performs poorly and is particularly ineffective for larger values of $k$. Additionally, the real-time random walk with drift models that we estimate never yields predictions as accurate as those based on our autoregressive type models.

Finally, note that MSFEs associated with the "best" models for money (i.e., Model C) largely decrease as $k$ increases. This is consistent with the view that using "latest available" data that have been revised as much as possible, when forming model coefficient estimates, leads to estimates that are more accurate (in the sense that releases used in coefficient construction are more efficient and/or may have less measurement error and are hence "closer" to their "true" values), when the objective is the prediction of later release or even "final" data. This in turn suggests that later releases of data should be predicted more accurately using Model C (as is indeed the case for money, where Model $\mathrm{C}$ is actually the MSFE-best model), but not necessarily when using other models. Indeed, notice that for prices, where Model A wins, the MSFEs actually increase as one increases $k$ from 2 to 3 to 4 , before beginning to decrease. The same sort of mixed pattern of increasing and decreasing MSFEs characterizes output.

\subsection{Data Rationality}

Tables A1.1-A1.3 repeat the above experiments, but add revision errors into the mix, hence allowing us to assess rationality from a different perspective. If revision errors are useful in ex-ante predictions of the sort that we report on in our tables, then we have direct evidence of inefficiency. To aid in the presentation of our results, bold numbers highlight experiments in which the inclusion of revision errors lowers the MSFE (see Tables 3-5). Starred entries in the tables denote cases in which a different model than the one found in Tables 3-5 obtains a lower MSFE. Consider the case of prices (see Table A1.2). Point MSFEs reported for Model A in this case are often lower than the comparable MSFEs reported in Table 4. This is a very interesting result, suggesting that early price releases are actually irrational and that the reason Model A "wins" in Table 4 is that the use of mixed release data associated with the estimation and implementation of Model $\mathrm{C}$ is simply "too costly" relative to the predictive accuracy losses associated with using mildly irrational first release data. This finding is consistent with the finding that prices are irrational when extant tests in the literature are carried out (see, e.g., Corradi, Fernandez, and Swanson (2009)). Of course, the results in Table A1.2 also suggest that there is information in the revision process for prices, again in accord with the result from the application of extant tests that prices are irrational. This constitutes further evidence of the importance of collecting real-time datasets. However, although point MSFEs are lower in virtually every case (when considering Model A) when $u_{C_{1}}$ and $u_{C_{2}}$ are 
included, the absolute magnitude of the difference in MSFEs is rather small, suggesting that the difference is likely insignificant. Moreover, examination of Tables A1.1 and A1.3 suggests that there is little information in the revision processes for the other two variables.

For the case of output, notice that in Table A1.1, MSFEs are lower than those reported in Table 3 for only a small number of cases that correspond to the longest forecasting period starting in 1970:1, and where Model C is now preferred to Model A. Likewise, for the case of money (see Table A1.3), there is no clear evidence to indicate that the revision process is useful when predicting money, particularly when the two longest forecasting periods are used. This is consistent with our earlier findings and those reported in Corradi, Fernandez, and Swanson (2009) that money is rational.

\subsection{Real-Time Marginal Predictive Content of Money for Output}

There are many noteworthy empirical analyses in the literature that present evidence concerning the empirical usefulness of real-time datasets. A key early paper that underscores the importance of revisions for predicting industrial production is Diebold and Rudebusch (1991). Hamilton and Perez-Quiros expand on results in the Diebold and Rudebusch paper by asking the question: "What do the leading indicators lead?" These authors find that simple linear models that include leading indicators are useful for predicting GDP. Further empirical evidence on the usefulness of real-time data is discussed in Bernanke and Boivin (2003), Gilbert (2009), Franses (2009), Franses and Segers (2009), and the references cited therein. In the empirical analysis reported on in this paper, we implement vector versions of Models $\mathrm{A}$ and $\mathrm{C}$ to examine whether money and revision errors from money and other variables have marginal predictive content for output. Results are gathered in Table 6 and correspond to those reported in Table 3, except that vector autoregressions are estimated rather than autoregressions and the target variable to be predicted is output. Note that models with and without money (and revision errors of money) are estimated. The number of lags in the regression models for output, money, prices, and interest rates is selected using the SIC. For related studies, see Amato and Swanson (2001) and Garratt, Koop, Mise, and Vahey (2009).

Following the notation used in Section 3.1, the models that we examine are:

Model A (output equation from associated vector autoregression):

$$
\begin{array}{r}
{ }_{t+k} Y_{t+1}=\alpha+\sum_{i=1}^{p} \beta_{i, t+2-i, t}^{A, Y} Y_{t+1-i}+\theta\left[{ }_{t+1} Y_{t-1}-{ }_{t} Y_{t-1}\right]+\sum_{i=1}^{p} \beta_{i, t+2-i, t}^{A, P} P_{t+1-i}+\sum_{i=1}^{p} \beta_{i, t+2-i, t}^{A, M} M_{t+1-i}+ \\
\sum_{i=1}^{p} \beta_{i, t+2-i, t}^{A, R} R_{t+1-i}+\theta_{t+1}^{\prime} W_{t}+\varepsilon_{t+k}
\end{array}
$$


Model C:(output equation from associated vector autoregression):

$$
\begin{aligned}
{ }_{t+k} Y_{t+1}=\alpha+\sum_{i=1}^{p} \beta_{i t+1}^{C, Y} Y_{t+1-i}+\theta\left[{ }_{t+1} Y_{t-1}-{ }_{t} Y_{t-1}\right]+\sum_{i=1}^{p} \beta_{i t+1}^{C, P} P_{t+1-i}+ & \sum_{i=1}^{p} \beta_{i t+1}^{C, M} M_{t+1-i}+ \\
& \sum_{i=1}^{p} \beta_{i t+1}^{C, R} R_{t+1-i}+\theta_{t+1}^{\prime} W_{t}+\varepsilon_{t+k},
\end{aligned}
$$

where $W_{t}={ }_{t+1} u_{t-1}^{t}$ or $W_{t}=\left({ }_{t+1} u_{t-1}^{t},{ }_{t} u_{t-2}^{t-1}\right)^{\prime}$, corresponding to the two cases considered (the two cases are denoted $u_{C_{1}}$ and $u_{C_{2}}$ in Table 6, respectively), ${ }_{t+1} u_{t-1}^{t}={ }_{t+1} Y_{t-k}-{ }_{t} Y_{t-k}$, for $k=1,2$.

Entries in Table 6 are MSFEs, and starred entries denote rejection of the Diebold-Mariano null hypothesis of equal predictive accuracy at a $10 \%$ level, using standard normal critical values, and assuming that the benchmark model is the simple autoregression given as Model A in Table 3. Entries in bold denote the lowest MSFEs across all models reported on in the table, for a given value of $k$. Finally, entries in italics are MSFE-best across all models that include money, for a given value of $k$.

On inspection of Table 6 , it is clear that it is always the case that (regardless of sample period, model, and vintage) the models with money yield higher MSFEs than the models without money (entries that are in bold denote MSFE-best models). This result holds for Models A and C, regardless of whether or not revision errors are included. Thus, at least based on the comparison of point MSFEs, there is evidence that money does not contain any marginal predictive content for output. This result should be viewed with caution, however, unless the sole purpose of the modeler is to predict output as accurately as possible. In particular, when carrying out policy analysis, for example, one often aims to include control variables that the government can manipulate. Simply specifying an autoregressive model has little use in such cases. For this reason, a better measure of the usefulness of money might be whether these money can be added to the prediction model without worsening predictive performance. If such is the case, then one has evidence that increased parameter and model uncertainty associated with including extra explanatory variables does not worsen predictive performance, hence suggesting that the "bigger" model is "adequately" specified. In light of this argument, note that the lack of starred entries associated with the MSFE-best models in Table 6 (i.e., see entries in bold in the table) for values of $k$ greater than 3 suggests the "adequacy" of vector autoregression models for predicting later release data. This is because the failure of the DM test to reject the null of equal predictive accuracy implies that nothing is lost by moving from a simple autoregression to a vector autoregression. However, this result still tells us nothing about the "adequacy" of models with money. For this reason, we examine the 
"adequacy" of our models with money by italicizing the MSFE-best models that include money for each release. Interestingly, for our longer prediction periods beginning in 1971 and 1983, models with money do not appear to be "adequate", as the autoregression models yield significantly more accurate predictions, as indicated by the fact that all italicized entries are starred (indicating that the simpler autoregressive model is preferred). However, for the shortest forecast period from 1990, the MSFE-best models with money are "adequate" for all releases except first release data, since in these cases the DM test does not find evidence that simple autoregressive models without models yield more accurate predictions (see the second row of entries in the third panel of the table).

Also interesting is the fact that when considering VAR models, output is always best predicted using varieties of Model A, regardless of release being predicted, placing this variable together with prices as being variables for which use of preliminary data yields the most accurate predictions. Needless to say, the findings of this illustration suggest that there is much to be learned via analysis of real-time datasets, yet again underscoring the importance of building and maintaining such datasets.

\section{Concluding Remarks}

Real-time data are used in this paper to shed new light on the importance of data rationality and definitional change, when the objective is the construction of prediction models for a given release of a variable. Many of our conclusions would not have been possible without the availability of real-time datasets, underscoring the importance of collecting and maintaining such datasets. For example, the data rationality test that we propose can only be implemented with real-time data.

Some of our findings include the following. For prices, first available data are MSFE-best for predicting any release, while models estimated using "latest release" data are MSFE-best when predicting any release of money (supporting a conclusion of irrationality). Interestingly, one of the main reasons for the latter finding turns out not to be a lack of efficiency, but rather a problem associated with the presence of definitional breaks to the money data that result in the "contamination" of time series constructed using only early releases. In effect, if definitional breaks are too substantial, then the use of early release data is tantamount to forming time series by concatenating data from various different DGPs. These definitional break problems also appear to be a issue for output, but not for prices.

In an empirical illustration, we find little marginal predictive content in money. However, we note that vector autoregressions with money do not perform significantly worse than autoregres- 
sions, when predicting output in the past 20 years.

Many problems in this literature remain unresolved. For example, from an empirical perspective it remains to extend the analysis that we carry out to more releases of data and to other variables in order to further examine the importance of definitional change. From a theoretical perspective, it remains to examine the properties of various predictive accuracy tests in the recursive and real-time framework employed in this paper. 


\section{References}

Amato, J. and N.R. Swanson (2001), The Real-Time Predictive Content of Money for Output, Journal of Monetary Economics 48, 3-24.

Aruoba, S.B. (2008), Real-Time Measurement of Business Conditions, Journal of Business and Economic Statistics, forthcoming.

Aruoba, S.B., F.X. Diebold and C. Scotti (2008), Data Revisions are not Well-Behaved, Journal of Money, Credit and Banking 40, 319-340.

Ashley, R., C.W.J., Granger and R. Schmalensee, (1980), Advertising and Aggregate Consumption: An Analysis of Causality, Econometrica, 48, 1149-1167.

Bernanke, B.S. and J. Boivin (2003), Monetary Policy in a Data-Rich Environment, Journal of Monetary Economics 50, 525-546.

Chao, J., V. Corradi and N.R. Swanson (2001), An out-of-sample Test for Granger Causality, Macroeconomic Dynamics 5, 598-620.

Clark, T.E., and M.W. McCracken (2001), Tests of Equal Forecast Accuracy and Encompassing for Nested Models, Journal of Econometrics 105, 85-110.

Clark, T.E., and M.W. McCracken (2005), Evaluating Direct Multistep Forecasts, Econometric Reviews 24, 369-404.

Clark, T. E. and M.W. McCracken (2009), Tests of Equal Predictive Ability with Real-Time Data, Journal of Business 8 Economic Statistics, forthcoming.

Corradi, V. and N.R., Swanson, (2002), A Consistent Test for Out of Sample Nonlinear Predictive Ability", Journal of Econometrics, 110, 353-381.

Corradi, V. A. Fernandez, and N.R. Swanson (2009), Information in the Revision Process of Real-Time Datasets, Journal of Business $\&$ Economic Statistics, forthcoming.

Corradi, V. and N.R. Swanson (2006), Predictive Density Evaluation, in: Handbook of Economic Forecasting, eds. Clive W.J. Granger, Graham Elliot and Allan Timmermann, Elsevier, Amsterdam, pp. 197-284.

Croushore, D. (2006), Forecasting with Real-Time Macroeconomic Data, in: Handbook of Economic Forecasting, eds. Clive W.J. Granger, Graham Elliot and Allan Timmermann, Elsevier, Amsterdam, pp. 961-982.

Croushore, D. and T. Stark (2001), A Real-Time Dataset for Macroeconomists, Journal of Econometrics 105, 111-130. 
Croushore, D. and T. Stark (2003), A Real-Time Dataset for Macroeconomists: Does Data Vintage Matter?, Review of Economics and Statistics 85, 605-617.

Diebold, F. X. and R.S. Mariano (1995), Comparing Predictive Accuracy, Journal of Business and Economic Statistics 13, 253-263.

Diebold, F.X. and G.D. Rudebusch (1991), Forecasting Output with the Composite Leading Index: A Real-Time Analysis, Journal of the American Statistical Association 86, 603-610.

Faust, J. and J. Wright (2009), Comparing Greenbook and Reduced Form Forecasts using a Large Realtime Dataset, Journal of Business $\&$ Economic Statistics, forthcoming.

Franses, P.H. (2009), Data Revisions and Periodic Properties of Macroeconomic Data, Working Paper, Erasmus University.

Franses, P.H. and R. Segers (2009), Seasonality in Revisions in Macroeconomic Data, Working Paper, Erasmus University.

Gallo, G.M. and M. Marcellino (1999), Ex Post and Ex Ante Analysis of Provisional Data, Journal of Forecasting 18, 421-433.

Garratt, A., G. Koop, E. Mise and S.P. Vahey (2009), Real-Time Prediction with UK Monetary Aggregates in the Presence of Model Uncertainty, Journal of Business and Economic Statistics, forthcoming.

Ghysels, E., N.R. Swanson and M. Callan (2002), Monetary Policy Rules with Model and Data Uncertainty, Southern Economic Journal 69, 239-265.

Gilbert, T. (2009), Information Aggregation Around Macroeconomic Announcements: The Link Between Revisions and Stock Returns, Working Paper, University of Washington.

Hamilton, J.D. and G. Perez-Quiros (1996), What Do the Leading Indicators Lead?, Journal of Business 69, 27-49.

Kavajecz, K.A. and S. Collins (1995), Rationality of Preliminary Money Stock Estimates, Review of Economics and Statistics 77, 32-41.

Keane, M.P. and D.E. Runkle (1990), Testing the Rationality of Price Forecasts: New Evidence from Panel Data, American Economic Review 80, 714-735.

Mankiw, N.G., D.E. Runkle, and M.D. Shapiro (1984), Are Preliminary Announcements of the Money Stock Rational Forecasts?, Journal of Monetary Economics 14, 15-27.

Mankiw, N.G. and M.D. Shapiro (1986), News or Noise: an Analysis of GNP Revisions, Survey of Current Business 66, 20-25.

Mariano, R.S. and H. Tanizaki (1995), Prediction of Final Data with Use of Preliminary and/or 
Revised Data, Journal of Forecasting 14, 351-380.

Mork, K.A. (1987), Ain't Behavin': Forecast Errors and Measurement Errors in Early GNP Estimates, Journal of Business \& Economic Statistics 5, 165-175.

Rathjens, P. and R.P Robins (1995), Do Government Agencies Use Public Data: the Case of GNP, Review of Economics and Statistics, 77, 170-172.

Robertson, J.C. and E.W. Tallman (1998), Data Vintages and Measuring Forecast Performance, Federal Reserve Bank of Atlanta Economic Review 83 (Fourth Quarter), 4-20.

Stock, J.H. and M.W. Watson (1989): Interpreting the Evidence on Money-Income Causality, Journal of Econometrics, 40, 161-181.

Swanson, N.R., E. Ghysels and M. Callan (1999), A Multivariate Time Series Analysis of the Data Revision Process for Industrial Production and the Composite Leading Indicator, in R.F. Engle and H. White, eds., Cointegration, Causality, and Forecasting: A Festschrift in Honour of Clive W.J. Granger, Oxford: Oxford University Press, pp. 45-75.

Swanson, N.R. and D. van Dijk (2006), Are Statistical Reporting Agencies Getting It Right? Data Rationality and Business Cycle Asymmetry, Journal of Business 63 Economic Statistics 24, $24-42$. 
Table 1: Growth Rate and Revision Error Summary Statistics - Output, Prices, and Money(*)

\begin{tabular}{|c|c|c|c|c|c|c|c|c|c|c|c|}
\hline$\overline{V r b l}$ & Vint & $R-E r r$ & smpl & $\bar{y}$ & $\widehat{\sigma}_{y}$ & $\widehat{\sigma}_{\bar{y}}$ & skew & kurt & $\overline{L B}$ & $J B$ & $\overline{A D D F}$ \\
\hline \multirow[t]{16}{*}{ Output } & 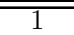 & " & $\bar{~} 65: 4$ & $\overline{0.00657}$ & $\overline{\overline{0.00790}}$ & 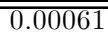 & -1.259 & "6.734 & "111.5 & "134.5 & -6.035 \\
\hline & 2 & - & $65: 4$ & 0.00705 & 0.00851 & 0.00066 & -1.148 & 6.678 & 107.1 & 123.8 & -6.350 \\
\hline & - & 1 & $65: 4$ & 0.00046 & 0.00189 & 0.00015 & 0.118 & 2.950 & 23.58 & 0.424 & -6.050 \\
\hline & - & 2 & $65: 4$ & -0.00002 & 0.00106 & 0.00008 & 0.324 & 8.982 & 32.01 & 237.0 & -5.471 \\
\hline & 1 & - & $70: 1$ & 0.00626 & 0.00817 & 0.00068 & -1.190 & 6.395 & 96.90 & 101.0 & -5.729 \\
\hline & 2 & - & $70: 1$ & 0.00675 & 0.00877 & 0.00073 & -1.111 & 6.446 & 92.42 & 98.05 & -4.911 \\
\hline & - & 1 & $70: 1$ & 0.00048 & 0.00193 & 0.00016 & 0.041 & 2.873 & 28.17 & 0.208 & -5.620 \\
\hline & - & 2 & $70: 1$ & -0.00001 & 0.00108 & 0.00009 & 0.300 & 9.087 & 27.70 & 216.9 & -5.128 \\
\hline & 1 & - & $83: 1$ & 0.00734 & 0.00486 & 0.00050 & 0.230 & 3.940 & 44.55 & 3.728 & -6.299 \\
\hline & 2 & - & $83: 1$ & 0.00766 & 0.00538 & 0.00056 & 0.379 & 3.958 & 53.06 & 5.179 & -6.178 \\
\hline & - & 1 & $83: 1$ & 0.00029 & 0.00171 & 0.00018 & -0.301 & 2.677 & 25.53 & 1.944 & -9.994 \\
\hline & - & 2 & $83: 1$ & 0.00012 & 0.00098 & 0.00010 & 1.753 & 9.658 & 14.73 & 207.4 & -9.753 \\
\hline & 1 & - & $90: 1$ & 0.00682 & 0.00463 & 0.00057 & -0.376 & 3.470 & 30.12 & 1.892 & -5.513 \\
\hline & 2 & - & $90: 1$ & 0.00724 & 0.00510 & 0.00063 & -0.195 & 3.277 & 38.83 & 0.490 & -5.508 \\
\hline & - & 1 & $90: 1$ & 0.00037 & 0.00161 & 0.00020 & -0.091 & 2.077 & 17.02 & 2.755 & -3.667 \\
\hline & - & 2 & $90: 1$ & 0.00008 & 0.00093 & 0.00012 & 2.090 & 12.60 & 13.24 & 275.2 & -8.226 \\
\hline \multirow[t]{16}{*}{ Prices } & 1 & $=$ & $65: 4$ & 0.00958 & $\overline{0.00608}$ & 0.00047 & 1.163 & 4.093 & $\bar{~} 1040$ & 44.05 & -1.613 \\
\hline & 2 & - & $65: 4$ & 0.00988 & 0.00636 & 0.00049 & 1.245 & 4.272 & 925.4 & 51.79 & -1.463 \\
\hline & - & 1 & $65: 4$ & 0.00026 & 0.00114 & 0.00009 & 1.235 & 7.277 & 35.13 & 160.8 & -5.384 \\
\hline & - & 2 & $65: 4$ & -0.00001 & 0.00054 & 0.00004 & -1.335 & 13.30 & 10.61 & 745.4 & -12.93 \\
\hline & 1 & - & $70: 1$ & 0.00968 & 0.00638 & 0.00052 & 1.093 & 3.716 & 955.5 & 31.43 & -1.411 \\
\hline & 2 & - & $70: 1$ & 0.01001 & 0.00666 & 0.00055 & 1.173 & 3.884 & 852.6 & 37.00 & -1.274 \\
\hline & - & 1 & $70: 1$ & 0.00029 & 0.00118 & 0.00010 & 1.175 & 6.844 & 33.78 & 118.5 & -4.891 \\
\hline & - & 2 & $70: 1$ & -0.00003 & 0.00055 & 0.00005 & -1.484 & 13.28 & 12.24 & 669.0 & -9.487 \\
\hline & 1 & - & $83: 1$ & 0.00624 & 0.00297 & 0.00030 & 0.471 & 2.992 & 191.9 & 3.429 & -1.998 \\
\hline & 2 & - & $83: 1$ & 0.00646 & 0.00296 & 0.00030 & 0.424 & 2.693 & 192.4 & 3.256 & -1.699 \\
\hline & - & 1 & $83: 1$ & 0.00020 & 0.00096 & 0.00010 & 1.423 & 10.95 & 16.40 & 264.2 & -8.831 \\
\hline & - & 2 & $83: 1$ & -0.00001 & 0.00053 & 0.00006 & -1.506 & 17.27 & 14.99 & 783.4 & -7.982 \\
\hline & 1 & - & $90: 1$ & 0.00528 & 0.00261 & 0.00032 & 0.872 & 4.549 & 50.94 & 13.71 & -1.914 \\
\hline & 2 & - & $90: 1$ & 0.00553 & 0.00252 & 0.00031 & 0.661 & 3.499 & 60.61 & 5.018 & -1.285 \\
\hline & - & 1 & $90: 1$ & 0.00023 & 0.00083 & 0.00010 & 2.748 & 17.87 & 13.34 & 644.4 & -7.535 \\
\hline & - & 2 & $90: 1$ & -0.00004 & 0.00056 & 0.00007 & -2.321 & 18.07 & 13.61 & 627.0 & -8.304 \\
\hline \multirow[t]{16}{*}{ Money } & $\overline{1}$ & $=$ & 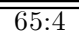 & $=0.01207$ & $\overline{0.01200}$ & $\overline{0.00093}$ & 0.077 & $\overline{\overline{3.119}}$ & $\overline{\overline{169.2}}$ & $\overline{0.209}$ & $\overline{-3.364}$ \\
\hline & 2 & - & $65: 4$ & 0.01240 & 0.01191 & 0.00093 & 0.097 & 3.169 & 173.2 & 0.374 & -4.922 \\
\hline & - & 1 & $65: 4$ & 0.00018 & 0.00135 & 0.00011 & 1.800 & 12.30 & 15.50 & 660.0 & -13.33 \\
\hline & - & 2 & $65: 4$ & 0.00009 & 0.00113 & 0.00009 & 1.316 & 14.54 & 11.80 & 923.2 & -12.13 \\
\hline & 1 & - & $70: 1$ & 0.01221 & 0.01244 & 0.00103 & 0.068 & 2.983 & 166.7 & 0.131 & -4.488 \\
\hline & 2 & - & $70: 1$ & 0.01256 & 0.01235 & 0.00103 & 0.088 & 3.029 & 170.3 & 0.187 & -4.464 \\
\hline & - & 1 & $70: 1$ & 0.00018 & 0.00140 & 0.00012 & 1.785 & 11.72 & 16.31 & 521.8 & -12.67 \\
\hline & - & 2 & $70: 1$ & 0.00005 & 0.00117 & 0.00010 & 1.344 & 14.26 & 10.67 & 782.4 & -11.62 \\
\hline & 1 & - & $83: 1$ & 0.01085 & 0.01403 & 0.00145 & 0.283 & 2.682 & 159.2 & 1.783 & -3.108 \\
\hline & 2 & - & $83: 1$ & 0.01120 & 0.01391 & 0.00144 & 0.301 & 2.728 & 163.1 & 1.805 & -3.131 \\
\hline & - & 1 & $83: 1$ & & & & 2.155 & 12.96 & 11.76 & 438.3 & -10.04 \\
\hline & - & 2 & $83: 1$ & 0.00009 & 0.00090 & 0.00009 & -0.056 & 7.032 & 19.05 & 58.43 & -9.292 \\
\hline & 1 & - & $90: 1$ & 0.00788 & 0.01302 & 0.00160 & 0.360 & 2.955 & 162.5 & 1.437 & -2.218 \\
\hline & 2 & - & $90: 1$ & 0.00827 & 0.01302 & 0.00161 & 0.454 & 3.170 & 159.7 & 2.188 & -2.273 \\
\hline & - & 1 & $90: 1$ & 0.00009 & 0.00139 & 0.00017 & 1.383 & 9.642 & 16.40 & 131.0 & -8.506 \\
\hline & - & 2 & $90: 1$ & 0.00001 & 0.00095 & 0.00012 & -0.488 & 6.006 & 18.34 & 24.04 & -7.682 \\
\hline
\end{tabular}

(*) Summary statistics are reported for a generic variable denoted by $y$, where $y=$ output, price, and money growth rates (see table rows where vint $=1,2$, corresponding to first and second available data), as well where $y=$ the revision error associated with these variables (see table rows where $R$-Err $=1,2$, corresponding to revision errors associated with second and third available data - i.e., ${ }_{t+2} u_{t}^{t+1}$ and ${ }_{t+3} u_{t}^{t+2}$ ). Statistics are reported for samples beginning in 1970:1, 1983:1, and 1990:1. All samples end in 2006:4. Additionally, $\bar{y}$ is the mean of the series, $\widehat{\sigma}_{y}$ is the standard error of the series, $\widehat{\sigma}_{\bar{y}}$ is the standard error of $\bar{y}$, skew is skewness, kurt is kurtosis, LB is the Ljung-Box statistic, $J B$ is the Jarques-Bera statistic, and $A D F$ is the augmented Dickey-Fuller statistic, where lag augmentations are selected via use of the Schwarz information criterion. See Sections 4 and 5 for further details. 
Table 2: Growth Rate and Revision Error Summary Statistics Based on Various Subsamples -

$$
\text { Output }^{(*)}
$$

\begin{tabular}{|c|c|c|c|c|c|c|c|c|c|c|c|}
\hline$\overline{V r b l}$ & $\overline{V i n t}$ & $R-E r r$ & smpl & $\bar{y}$ & $\widehat{\sigma}_{y}$ & $\widehat{\sigma}_{\bar{y}}$ & skew & kurt & $L B$ & $J B$ & $\overline{A D F}$ \\
\hline & $\overline{1}$ & - & $765: 4-06: 4$ & 0.00657 & 0.00790 & $\overline{0.00061}$ & -1.259 & 6.734 & 111.5 & 134.53 & -6.035 \\
\hline & 2 & - & $65: 4-06: 4$ & 0.00705 & 0.00851 & 0.00066 & -1.148 & 6.678 & 107.1 & 123.88 & -6.350 \\
\hline & - & 1 & $65: 4-06: 4$ & 0.00046 & 0.00189 & 0.00015 & 0.118 & 2.950 & 23.58 & 0.424 & -6.050 \\
\hline & - & 2 & $65: 4-06: 4$ & -0.00002 & 0.00106 & 0.00008 & 0.324 & 8.982 & 32.01 & 237.04 & -5.471 \\
\hline & 1 & - & $65: 4-75: 4$ & 0.00628 & 0.01114 & 0.00027 & -1.139 & 4.566 & 55.42 & 11.33 & -3.424 \\
\hline & 2 & - & $65: 4-75: 4$ & 0.00613 & 0.01169 & 0.00029 & -1.273 & 4.595 & 64.44 & 13.14 & -3.082 \\
\hline & - & 1 & $65: 4-75: 4$ & 0.00035 & 0.00191 & 0.00005 & 0.498 & 3.306 & 8.750 & 1.572 & -3.198 \\
\hline & - & 2 & $65: 4-75: 4$ & -0.00008 & 0.00094 & 0.00002 & -0.776 & 7.838 & 2.908 & 35.68 & -6.000 \\
\hline & 1 & - & $76: 1-80: 4$ & 0.00655 & 0.00976 & 0.00049 & -1.559 & 5.774 & 30.36 & 11.02 & - \\
\hline & 2 & - & $76: 1-80: 4$ & 0.00876 & 0.01139 & 0.00057 & -1.125 & 5.292 & 53.24 & 6.246 & - \\
\hline & - & 1 & $76: 1-80: 4$ & 0.00096 & 0.00199 & 0.00010 & 0.478 & 2.565 & 9.755 & 1.002 & - \\
\hline & - & 2 & $76: 1-80: 4$ & -0.00064 & 0.00134 & 0.00007 & -1.722 & 4.246 & 20.36 & 8.506 & - \\
\hline & 1 & - & $81: 1-85: 4$ & 0.00632 & 0.00998 & 0.00050 & -0.301 & 2.234 & 29.88 & 1.065 & - \\
\hline & 2 & - & $81: 1-85: 4$ & 0.00680 & 0.01044 & 0.00052 & -0.074 & 2.425 & 25.95 & 0.564 & - \\
\hline & - & 1 & $81: 1-85: 4$ & 0.00062 & 0.00259 & 0.00013 & 0.150 & 2.024 & 7.350 & 1.169 & - \\
\hline & - & 2 & $81: 1-85: 4$ & -0.00003 & 0.00072 & 0.00004 & 0.470 & 8.664 & 8.102 & 18.65 & - \\
\hline & 1 & - & $86: 1-91: 4$ & 0.00496 & 0.00450 & 0.00019 & -0.938 & 4.512 & 25.33 & 4.410 & -0.172 \\
\hline & 2 & - & $86: 1-91: 4$ & 0.00493 & 0.00466 & 0.00019 & -0.831 & 3.318 & 39.97 & 2.434 & 0.480 \\
\hline & - & 1 & $86: 1-91: 4$ & -0.00009 & 0.00184 & 0.00008 & -0.764 & 2.941 & 4.842 & 2.051 & -5.982 \\
\hline & - & 2 & $86: 1-91: 4$ & 0.00027 & 0.00104 & 0.00004 & 1.732 & 6.962 & 5.392 & 2.646 & 3.532 \\
\hline & 1 & - & $92: 1-95: 4$ & 0.00643 & 0.00375 & 0.00022 & 0.212 & 2.412 & 18.59 & 4.410 & - \\
\hline & 2 & - & $92: 1-95: 4$ & 0.00738 & 0.00406 & 0.00024 & 0.482 & 2.974 & 7.951 & 2.434 & - \\
\hline & - & 1 & $92: 1-95: 4$ & 0.00101 & 0.00134 & 0.00008 & -1.289 & 4.629 & 8.588 & 4.045 & - \\
\hline & - & 2 & $92: 1-95: 4$ & -0.00008 & 0.00045 & 0.00003 & -3.262 & 12.266 & 2.044 & 58.55 & - \\
\hline & 1 & - & $96: 1-97: 1$ & 0.00854 & - & - & - & - & - & - & - \\
\hline & 2 & - & $96: 1-97: 1$ & 0.00569 & - & - & - & - & - & - & - \\
\hline & - & 1 & $96: 1-97: 1$ & -0.00027 & - & - & - & - & - & - & - \\
\hline & - & 2 & $96: 1-97: 1$ & 0.00005 & - & - & - & - & - & - & - \\
\hline & 1 & - & $97: 2-99: 3$ & 0.00904 & - & - & - & - & - & - & - \\
\hline & 2 & - & $97: 2-99: 3$ & 0.00984 & - & - & - & - & - & - & - \\
\hline & - & 1 & $97: 2-99: 3$ & 0.00048 & - & - & - & - & - & - & - \\
\hline & - & 2 & $97: 2-99: 3$ & -0.00008 & - & - & - & - & - & - & - \\
\hline & 1 & - & $99: 4-00: 1$ & 0.01293 & - & - & - & - & - & - & - \\
\hline & 2 & - & $99: 4-00: 1$ & 0.00922 & - & - & - & - & - & - & - \\
\hline & - & 1 & $99: 4-00: 1$ & 0.00202 & - & - & - & - & - & - & - \\
\hline & - & 2 & $99: 4-00: 1$ & 0.00000 & - & - & - & - & - & - & - \\
\hline & 1 & - & $00: 2-03: 4$ & 0.00639 & 0.00551 & 0.00037 & 0.638 & 2.193 & 17.55 & 1.570 & - \\
\hline & 2 & - & $00: 2-03: 4$ & 0.00641 & 0.00562 & 0.00037 & 0.369 & 2.397 & 12.48 & 0.796 & - \\
\hline & - & 1 & $00: 2-03: 4$ & 0.00001 & 0.00184 & 0.00012 & 0.477 & 1.995 & 6.526 & 1.380 & - \\
\hline & - & 2 & $00: 2-03: 4$ & 0.00050 & 0.00101 & 0.00007 & 1.438 & 3.144 & 10.22 & 3.911 & - \\
\hline & 1 & - & $04: 1-06: 4$ & 0.00786 & 0.00258 & 0.00022 & -0.614 & 2.671 & 10.62 & 0.866 & - \\
\hline & 2 & - & $04: 1-06: 4$ & 0.00998 & 0.00386 & 0.00032 & 1.152 & 4.678 & 22.72 & 0.866 & - \\
\hline & - & 1 & $04: 1-06: 4$ & 0.00089 & 0.00068 & 0.00006 & 0.003 & 1.920 & 6.137 & 0.914 & - \\
\hline & - & 2 & $04: 1-06: 4$ & -0.00008 & 0.00042 & 0.00003 & -2.613 & 8.421 & 3.170 & 16.59 & - \\
\hline
\end{tabular}

(*) See notes to Table 1. Subsamples were chosen by examining plots of various calendar dates (including 1959:4, 1960:4, 1961:4, and 1962:4) across all vintages from 1964:4-2006:4, and by defining "breaks" to be points where the historical data changed. See Section 4 and 5 for further details. 
Table 3: MSFEs Calculated Based on Simple Real-Time Autoregressions Without Revision Errors

\begin{tabular}{|c|c|c|c|c|c|c|c|}
\hline Model & RevErr & $k=2$ & $k=3$ & $k=4$ & $k=6$ & $k=12$ & $k=24$ \\
\hline \multicolumn{8}{|c|}{ Panel A: Mean Square Forecast Errors } \\
\hline \multicolumn{8}{|c|}{ Begin Date of Forecast Period $=1970: 1$} \\
\hline $\bar{A}$ & None & 0.642 & 0.783 & 0.825 & 0.841 & 0.839 & 0.836 \\
\hline B & None & 0.642 & 0.983 & 1.028 & 1.232 & 1.090 & 1.134 \\
\hline C & None & 0.661 & 0.792 & 0.825 & 0.828 & 0.817 & 0.815 \\
\hline RWD-A & None & 0.768 & 0.879 & 0.890 & 0.861 & 0.833 & 0.843 \\
\hline RWD-B & None & 0.768 & 0.896 & 0.916 & 0.905 & 0.846 & 0.925 \\
\hline RWD-C & None & 0.766 & 0.874 & 0.884 & 0.856 & 0.829 & 0.838 \\
\hline \multicolumn{8}{|c|}{ Begin Date of Forecast Period $=1983: 1$} \\
\hline $\mathrm{A}$ & None & 0.212 & 0.259 & 0.270 & 0.303 & 0.322 & 0.354 \\
\hline B & None & 0.212 & 0.303 & 0.322 & 0.490 & 0.466 & 0.573 \\
\hline C & None & 0.206 & 0.259 & 0.267 & 0.299 & 0.316 & 0.346 \\
\hline RWD-A & None & 0.275 & 0.337 & 0.345 & 0.374 & 0.382 & 0.419 \\
\hline RWD-B & None & 0.275 & 0.326 & 0.337 & 0.359 & 0.345 & 0.363 \\
\hline RWD-C & None & 0.248 & 0.309 & 0.314 & 0.343 & 0.356 & 0.387 \\
\hline \multicolumn{8}{|c|}{ Begin Date of Forecast Period $=1990: 1$} \\
\hline A & None & 0.175 & 0.204 & 0.216 & 0.278 & 0.286 & 0.332 \\
\hline B & None & 0.175 & 0.247 & 0.236 & 0.343 & 0.432 & 0.491 \\
\hline $\mathrm{C}$ & None & 0.176 & 0.214 & 0.216 & 0.275 & 0.289 & 0.329 \\
\hline RWD-A & None & 0.224 & 0.275 & 0.270 & 0.322 & 0.327 & 0.371 \\
\hline RWD-B & None & 0.224 & 0.271 & 0.266 & 0.324 & 0.344 & 0.379 \\
\hline RWD-C & None & 0.208 & 0.258 & 0.250 & 0.304 & 0.319 & 0.356 \\
\hline \multicolumn{8}{|c|}{ Panel B: Diebold-Mariano Test Statistics Corresponding to Entries in Panel } \\
\hline \multicolumn{8}{|c|}{ Begin Date of Forecast Period $=1970: 1$} \\
\hline A & None & - & - & - & - & - & - \\
\hline B & None & - & -1.415 & -1.423 & -2.216 & -1.148 & -1.586 \\
\hline C & None & -0.349 & -0.159 & -0.008 & 0.213 & 0.348 & 0.368 \\
\hline RWD-A & None & -1.077 & -0.718 & -0.446 & -0.125 & 0.035 & -0.047 \\
\hline RWD-B & None & -1.077 & -0.811 & -0.589 & -0.359 & -0.041 & -0.470 \\
\hline RWD-C & None & -1.070 & -0.689 & -0.411 & -0.097 & 0.057 & -0.012 \\
\hline \multicolumn{8}{|c|}{ Begin Date of Forecast Period $=1983: 1$} \\
\hline A & None & - & - & - & - & - & - \\
\hline B & None & - & -1.096 & -1.056 & -2.558 & -2.467 & -2.542 \\
\hline $\mathrm{C}$ & None & 0.480 & -0.053 & 0.255 & 0.344 & 0.378 & 0.562 \\
\hline RWD-A & None & -1.525 & -1.826 & -1.718 & -1.688 & -1.568 & -1.582 \\
\hline RWD-B & None & -1.525 & -1.638 & -1.576 & -1.421 & -0.568 & -0.200 \\
\hline RWD-C & None & -0.989 & -1.366 & -1.242 & -1.181 & -1.001 & -0.936 \\
\hline \multicolumn{8}{|c|}{ Begin Date of Forecast Period $=1990: 1$} \\
\hline A & None & - & - & - & - & - & - \\
\hline B & None & - & -1.419 & -0.683 & -1.943 & -1.743 & -2.365 \\
\hline $\mathrm{C}$ & None & -0.060 & -0.570 & -0.039 & 0.166 & -0.149 & 0.157 \\
\hline RWD-A & None & -1.316 & -1.771 & -1.499 & -1.182 & -1.188 & -1.157 \\
\hline RWD-B & None & -1.316 & -1.557 & -1.336 & -1.075 & -1.027 & -0.764 \\
\hline RWD-C & None & -0.852 & -1.281 & -0.976 & -0.711 & -0.845 & -0.647 \\
\hline
\end{tabular}

${ }^{*}$ ) In Panel A, forecast mean square errors (MSFEs) are reported based on predictions constructed using recursively estimated models with estimation period beginning in 1965:4 and ex-ante prediction periods beginning in 1970:1, 1983:1, or 1990:1. Corresponding Diebold-Mariano predictive accuracy test statistics are reported in Panel B. In all cases, Model A is set as the "benchmark" model, so that a negative statistic means that Model A is "MSFE-better" than the particular model against which it is being compared. All estimated models are either pure autoregressions or autoregressions with revision error(s) included as additional explanatory variables. Lags are selected using the Schwarz Information Criterion. The pure autoregression models are: Model A (First Available Data), Model B ( $k^{\text {th }}$ Available Data), and Model C (Latest Available Data) (see Section 3.1 for complete details). In the models, X denotes the growth rate of either output, prices, or money. Also, RWD is the random walk with drift model in log levels, $u_{C 1}={ }_{t+1} u_{t-k}^{t}, k=1 ; u_{C 2}={ }_{t+1} u_{t-k}^{t}, k=1,2$; and $u_{C 3}={ }_{t+1} u_{t+1-k}^{t+2-k}, k=3$. Further details are contained in Sections 3 and 4 . 
Table 4: MSFEs Calculated Based on Simple Real-Time Autoregressions Without Revision Errors

\begin{tabular}{|c|c|c|c|c|c|c|c|}
\hline \multicolumn{8}{|c|}{ for $\operatorname{Prices}^{(*)}$} \\
\hline Model & RevErr & $k=2$ & $k=3$ & $k=4$ & $k=6$ & $k=12$ & $k=24$ \\
\hline \multicolumn{8}{|c|}{ Panel A: Mean Square Forecast Errors } \\
\hline \multicolumn{8}{|c|}{ Begin Date of Forecast Period $=1970: 1$} \\
\hline $\mathrm{A}$ & None & 0.149 & 0.166 & 0.167 & 0.163 & 0.139 & 0.125 \\
\hline B & None & 0.149 & 0.214 & 0.211 & 0.339 & 0.516 & 0.608 \\
\hline $\mathrm{C}$ & None & 0.160 & 0.179 & 0.182 & 0.178 & 0.151 & 0.137 \\
\hline RWD-A & None & 0.430 & 0.463 & 0.457 & 0.442 & 0.444 & 0.437 \\
\hline RWD-B & None & 0.430 & 0.486 & 0.489 & 0.495 & 0.557 & 0.739 \\
\hline RWD-C & None & 0.472 & 0.500 & 0.496 & 0.480 & 0.478 & 0.469 \\
\hline \multicolumn{8}{|c|}{ Begin Date of Forecast Period =1983:1 } \\
\hline $\mathrm{A}$ & None & 0.072 & 0.076 & 0.075 & 0.069 & 0.063 & 0.063 \\
\hline $\mathrm{B}$ & None & 0.072 & 0.077 & 0.076 & 0.088 & 0.257 & 0.556 \\
\hline $\mathrm{C}$ & None & 0.075 & 0.079 & 0.079 & 0.073 & 0.066 & 0.065 \\
\hline RWD-A & None & 0.395 & 0.376 & 0.374 & 0.362 & 0.349 & 0.360 \\
\hline RWD-B & None & 0.395 & 0.414 & 0.416 & 0.394 & 0.380 & 0.303 \\
\hline RWD-C & None & 0.512 & 0.488 & 0.486 & 0.474 & 0.458 & 0.469 \\
\hline \multicolumn{8}{|c|}{ Begin Date of Forecast Period =1990:1 } \\
\hline $\mathrm{A}$ & None & 0.057 & 0.047 & 0.050 & 0.049 & 0.040 & 0.043 \\
\hline B & None & 0.057 & 0.059 & 0.054 & 0.073 & 0.108 & 0.191 \\
\hline $\mathrm{C}$ & None & 0.061 & 0.051 & 0.053 & 0.053 & 0.042 & 0.043 \\
\hline RWD-A & None & 0.440 & 0.406 & 0.409 & 0.387 & 0.368 & 0.378 \\
\hline RWD-B & None & 0.440 & 0.447 & 0.455 & 0.426 & 0.419 & 0.388 \\
\hline RWD-C & None & 0.561 & 0.522 & 0.526 & 0.500 & 0.478 & 0.489 \\
\hline \multicolumn{8}{|c|}{ Panel B: Diebold-Mariano Test Statistics Corresponding to Entries in Panel A } \\
\hline \multicolumn{8}{|c|}{ Begin Date of Forecast Period =1970:1 } \\
\hline $\mathrm{A}$ & None & - & - & - & - & - & - \\
\hline B & None & - & -1.419 & -1.222 & -3.003 & -4.030 & -5.085 \\
\hline $\mathrm{C}$ & None & -0.704 & -0.758 & -0.788 & -0.826 & -0.807 & -0.741 \\
\hline RWD-A & None & -5.584 & -5.526 & -5.408 & -5.565 & -5.575 & -5.926 \\
\hline RWD-B & None & -5.584 & -5.802 & -5.647 & -5.648 & -5.614 & -5.647 \\
\hline RWD-C & None & -6.462 & -6.544 & -6.417 & -6.587 & -6.677 & -6.936 \\
\hline \multicolumn{8}{|c|}{ Begin Date of Forecast Period =1983:1 } \\
\hline $\mathrm{A}$ & None & - & - & - & - & - & - \\
\hline B & None & - & -0.061 & -0.074 & -1.589 & -2.627 & -3.793 \\
\hline $\mathrm{C}$ & None & -0.747 & -0.782 & -0.715 & -0.971 & -0.735 & -0.452 \\
\hline RWD-A & None & -8.740 & -8.298 & -8.206 & -8.827 & -8.798 & -8.741 \\
\hline RWD-B & None & -8.740 & -8.787 & -8.724 & -9.020 & -8.444 & -6.042 \\
\hline RWD-C & None & -9.928 & -9.616 & -9.594 & -10.408 & -10.37 & -10.06 \\
\hline \multicolumn{8}{|c|}{ Begin Date of Forecast Period =1990:1 } \\
\hline $\mathrm{A}$ & None & - & - & - & - & - & - \\
\hline B & None & - & -1.669 & -0.280 & -1.763 & -3.278 & -3.967 \\
\hline $\mathrm{C}$ & None & -0.703 & -0.983 & -0.429 & -0.628 & -0.341 & -0.171 \\
\hline RWD-A & None & -7.913 & -7.974 & -7.956 & -7.497 & -7.640 & -7.676 \\
\hline RWD-B & None & -7.913 & -8.341 & -8.378 & -7.720 & -7.768 & -7.149 \\
\hline RWD-C & None & -8.813 & -9.031 & -9.185 & -8.671 & -8.850 & -8.730 \\
\hline
\end{tabular}

(*) See notes to Table 3 . 
Table 5: MSFEs Calculated Based on Simple Real-Time Autoregressions Without Revision Errors

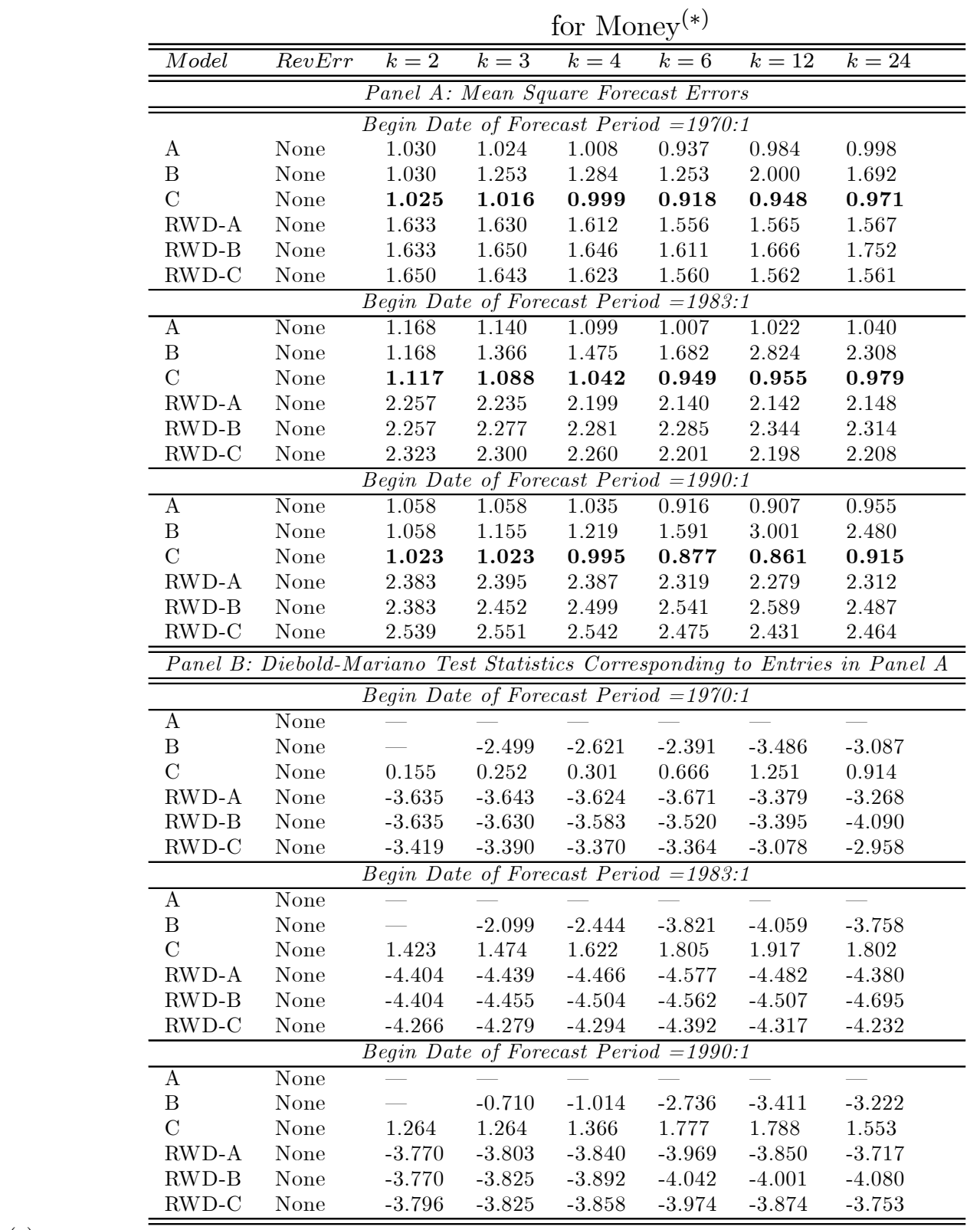

(*) See notes to Table 3. 
Table 6: MSFEs Calculated Based on Real-Time Vector Autoregressions With and Without

Money and Revision Errors ${ }^{(*)}$

\begin{tabular}{|c|c|c|c|c|c|c|c|}
\hline Model & RevErr & $k=2$ & $k=3$ & $k=4$ & $k=6$ & $k=12$ & $k=24$ \\
\hline \multicolumn{8}{|c|}{ Panel A: Mean Square Forecast Errors } \\
\hline \multicolumn{8}{|c|}{$\overline{\text { Begin Date of Forecast Period }=1971: 2}$} \\
\hline VAR - NoM Mod A & None & 0.866 & 1.004 & 1.031 & 1.049 & 1.088 & 1.083 \\
\hline VAR - M Mod A & None & $1.069^{*}$ & $1.196^{*}$ & $1.190^{*}$ & $1.200^{*}$ & $1.226^{*}$ & $1.235^{*}$ \\
\hline VAR - NoM Mod C & None & 0.889 & 1.027 & 1.054 & 1.049 & 1.074 & 1.042 \\
\hline VAR - M Mod C & None & 1.499 & 1.629 & 1.639 & 1.628 & 1.662 & 1.602 \\
\hline VAR - NoM Mod A & $u_{C 1}$ & 0.719 & 0.856 & 0.876 & 0.891 & 0.929 & 0.916 \\
\hline VAR - M Mod A & $u_{C 1}$ & 1.172 & 1.296 & 1.285 & 1.296 & 1.330 & 1.355 \\
\hline VAR - NoM Mod A & $u_{C 2}$ & 1.036 & 1.168 & 1.219 & 1.235 & 1.281 & 1.271 \\
\hline VAR - M Mod A & $u_{C 2}$ & 1.562 & 1.691 & 1.706 & 1.708 & 1.731 & 1.716 \\
\hline VAR - NoM Mod C & $u_{C 1}$ & 0.840 & 0.982 & 1.006 & 1.009 & 1.037 & 1.014 \\
\hline VAR - M Mod C & $u_{C 1}$ & 2.213 & 2.322 & 2.362 & 2.356 & 2.406 & 2.303 \\
\hline VAR - NoM Mod C & $u_{C 2}$ & 1.107 & 1.267 & 1.317 & 1.327 & 1.372 & 1.341 \\
\hline VAR - M Mod C & $u_{C 2}$ & 1.334 & 1.499 & 1.489 & 1.463 & 1.482 & 1.466 \\
\hline \multicolumn{8}{|c|}{ Begin Date of Forecast Period $=1983: 1$} \\
\hline VAR - NoM Mod A & None & 0.270 & $0.315^{*}$ & 0.322 & 0.342 & 0.338 & 0.366 \\
\hline VAR - M Mod A & None & $0.324 *$ & $0.378 *$ & $0.377 *$ & 0.396 & 0.389 & 0.409 \\
\hline VAR - NoM Mod C & None & 0.274 & 0.323 & 0.326 & 0.334 & 0.345 & $0.364^{*}$ \\
\hline VAR - M Mod C & None & 0.466 & 0.524 & 0.509 & 0.511 & 0.500 & 0.519 \\
\hline VAR - NoM Mod A & $u_{C 1}$ & $0.269 *$ & $0.315^{*}$ & 0.322 & 0.340 & 0.339 & 0.366 \\
\hline VAR - M Mod A & $u_{C 1}$ & $0.324^{*}$ & $0.378^{*}$ & 0.378 & 0.396 & 0.391 & 0.410 \\
\hline VAR - NoM Mod A & $u_{C 2}$ & 0.293 & 0.341 & 0.348 & 0.361 & 0.358 & 0.382 \\
\hline VAR - M Mod A & $u_{C 2}$ & 0.390 & 0.451 & 0.454 & 0.447 & 0.438 & 0.447 \\
\hline VAR - NoM Mod C & $u_{C 1}$ & $0.269 *$ & 0.319 & 0.320 & 0.328 & 0.346 & 0.364 \\
\hline VAR - M Mod C & $u_{C 1}$ & 0.454 & 0.512 & 0.496 & 0.505 & 0.504 & 0.518 \\
\hline VAR - NoM Mod C & $u_{C 2}$ & 0.278 & 0.325 & 0.328 & 0.336 & 0.354 & 0.371 \\
\hline VAR - M Mod C & $u_{C 2}$ & 0.516 & 0.585 & 0.567 & 0.562 & 0.546 & 0.561 \\
\hline \multicolumn{8}{|c|}{ Begin Date of Forecast Period $=1990: 1$} \\
\hline VAR - NoM Mod A & None & $0.227^{*}$ & 0.243 & 0.253 & 0.313 & 0.316 & 0.343 \\
\hline VAR - M Mod A & None & $0.241 *$ & 0.252 & 0.260 & 0.316 & 0.319 & 0.344 \\
\hline VAR - NoM Mod C & None & 0.242 & 0.266 & 0.265 & 0.313 & 0.333 & 0.344 \\
\hline VAR - M Mod C & None & 0.319 & 0.334 & 0.329 & 0.366 & 0.386 & 0.392 \\
\hline VAR - NoM Mod A & $u_{C 1}$ & 0.230 & 0.245 & 0.255 & 0.315 & 0.318 & 0.347 \\
\hline VAR - M Mod A & $u_{C 1}$ & $0.241^{*}$ & 0.253 & 0.261 & 0.317 & 0.319 & 0.346 \\
\hline VAR - NoM Mod A & $u_{C 2}$ & 0.239 & 0.254 & 0.265 & 0.323 & 0.326 & 0.351 \\
\hline VAR - M Mod A & $u_{C 2}$ & 0.253 & 0.264 & 0.273 & 0.327 & 0.329 & 0.351 \\
\hline VAR - NoM Mod C & $u_{C 1}$ & 0.235 & 0.258 & 0.258 & 0.308 & 0.329 & 0.343 \\
\hline VAR - M Mod C & $u_{C 1}$ & 0.326 & 0.338 & 0.333 & 0.378 & 0.404 & 0.413 \\
\hline VAR - NoM Mod C & $u_{C 2}$ & 0.246 & 0.270 & 0.270 & 0.316 & 0.336 & 0.343 \\
\hline VAR - M Mod C & $u_{C 2}$ & 0.332 & 0.349 & 0.344 & 0.387 & 0.412 & 0.417 \\
\hline
\end{tabular}

(*) See notes to Table 3. Vector autoregressions with and without money are used to predict real-time output. Entries are MSFEs, and starred entries denote rejection of the Diebold-Mariano null hypothesis of equal predictive accuracy at a $10 \%$ level, using standard normal critical values, and assuming that the benchmark model is Model A from Table 3. Entries in bold are the lowest MSFEs across all models reported on in the table, for a given value of $k$. Finally, entries in italics are MSFE-best across all models that include money, for a given value of $k$. See Section 3 of the paper for complete details. 
Figure 1: Output - Historical Data and Prediction Results
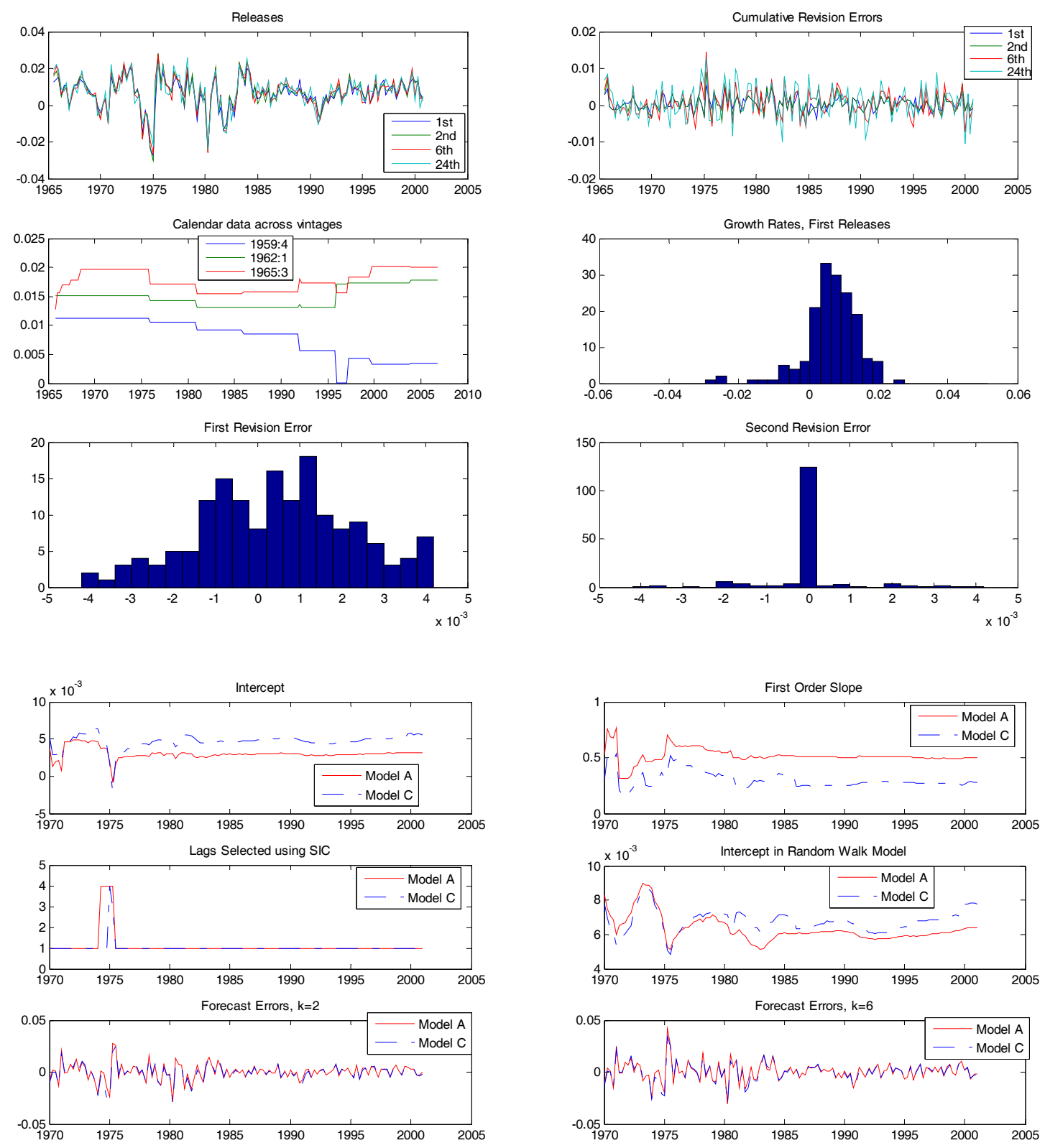

${ }^{(*)}$ Notes: The upper six panels describe the main properties of the real-time dataset for the growth rate of output (X) as follows: (i) "Releases" plots the time series for ${ }_{t+k} X_{t}, k=1,2,6,24$; "Cumulative Revision Errors" plots the time series for ${ }_{t+k} X_{t}-{ }_{t+1} X_{t}, k=1,2,6,24$; (iii) "Calendar data across vintages" plots the time series for three calendar dates across all available vintages, where the calendar dates are 1959:4+k$X_{1959: 4,1962: 1+k} X_{1962: 1,1965: 3+k} X_{1965: 3}$, for all $k$; (iv) "Growth Rates, First Releases" plots the distribution of ${ }_{t+1} X_{t}$ across the entire sample; and (v) "First" and "Second Revision Error" plots the distribution of ${ }_{t+2} X_{t}-{ }_{t+1} X_{t}$ and ${ }_{t+3} X_{t}-{ }_{t+2} X_{t}$, respectively. The lower six panels describe the main results from the recursive estimation of Models A and B as follows: (i) "Intercept", "First order Slope", and "Intercept in Random Walk Model" plot the recursive estimates of, respectively, $a_{t+1, t}^{M},{ }_{1, t+1, t}^{M}, a_{t+1, t}^{R W}$, for $M=A, B$, where $a_{t+1, t}^{R W M}$ is the slope of the random walk model associated to model $M$ (see notes to Table 3 ); (iii) "Lags Selected using SIC" reports the number of lags selected using the SIC across all recursively estimated models; and (iv) "Forecast Errors, $\mathrm{k}=2$ " and " $\mathrm{k}=6$ " report, respectively, ${ }_{t+k} X_{t}{ }{ }_{t+k} X_{t}^{M} k=2,6 ; M=A, B$, and ${ }_{t+k} X_{t}^{M}$, which is the one-step ahead forecast using model $M$. 
Figure 2: Prices - Historical Data and Prediction Results
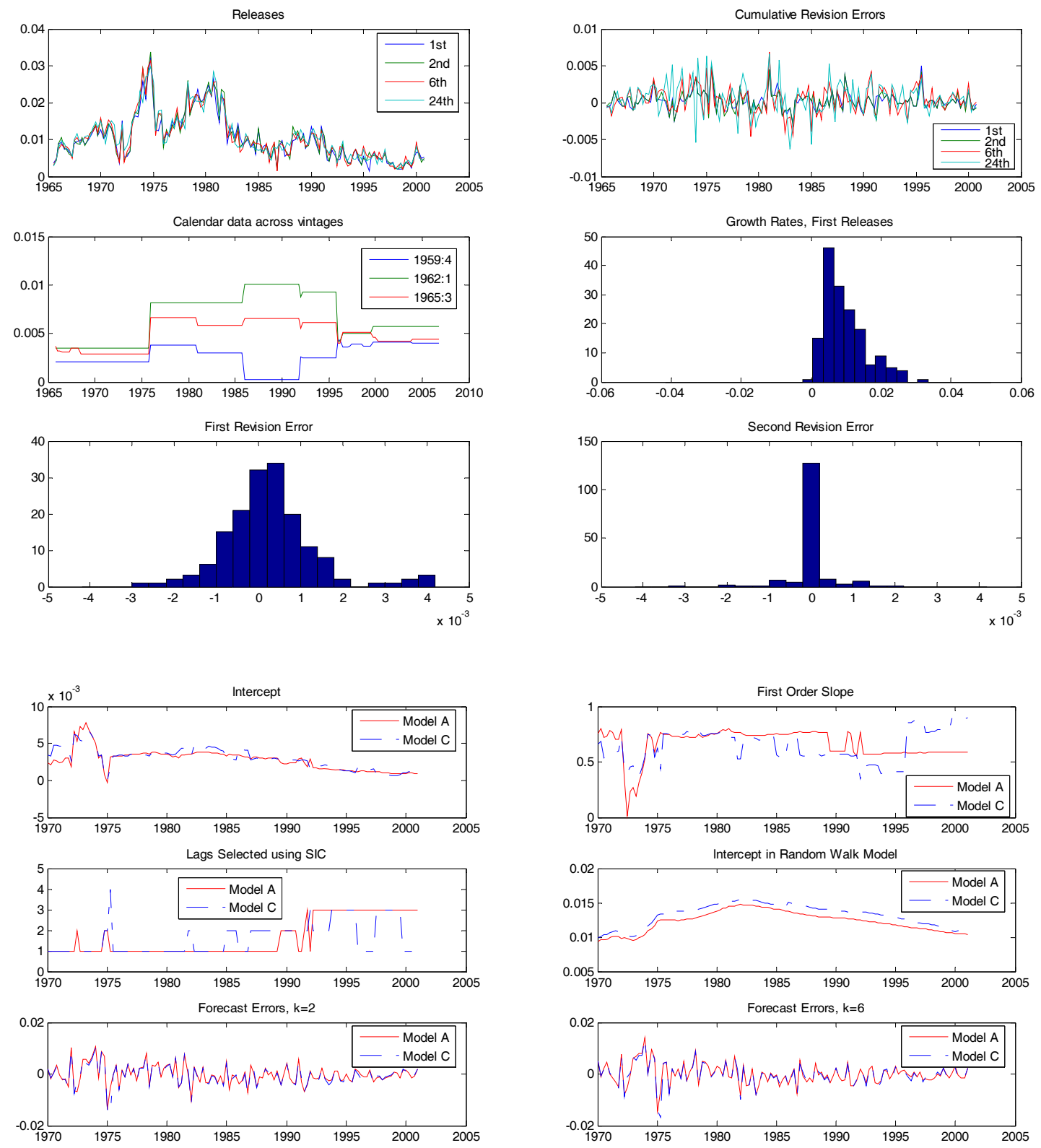

${ }^{(*)}$ Notes: See notes to Figure 1. 
Figure 3: Money - Historical Data and Prediction Results
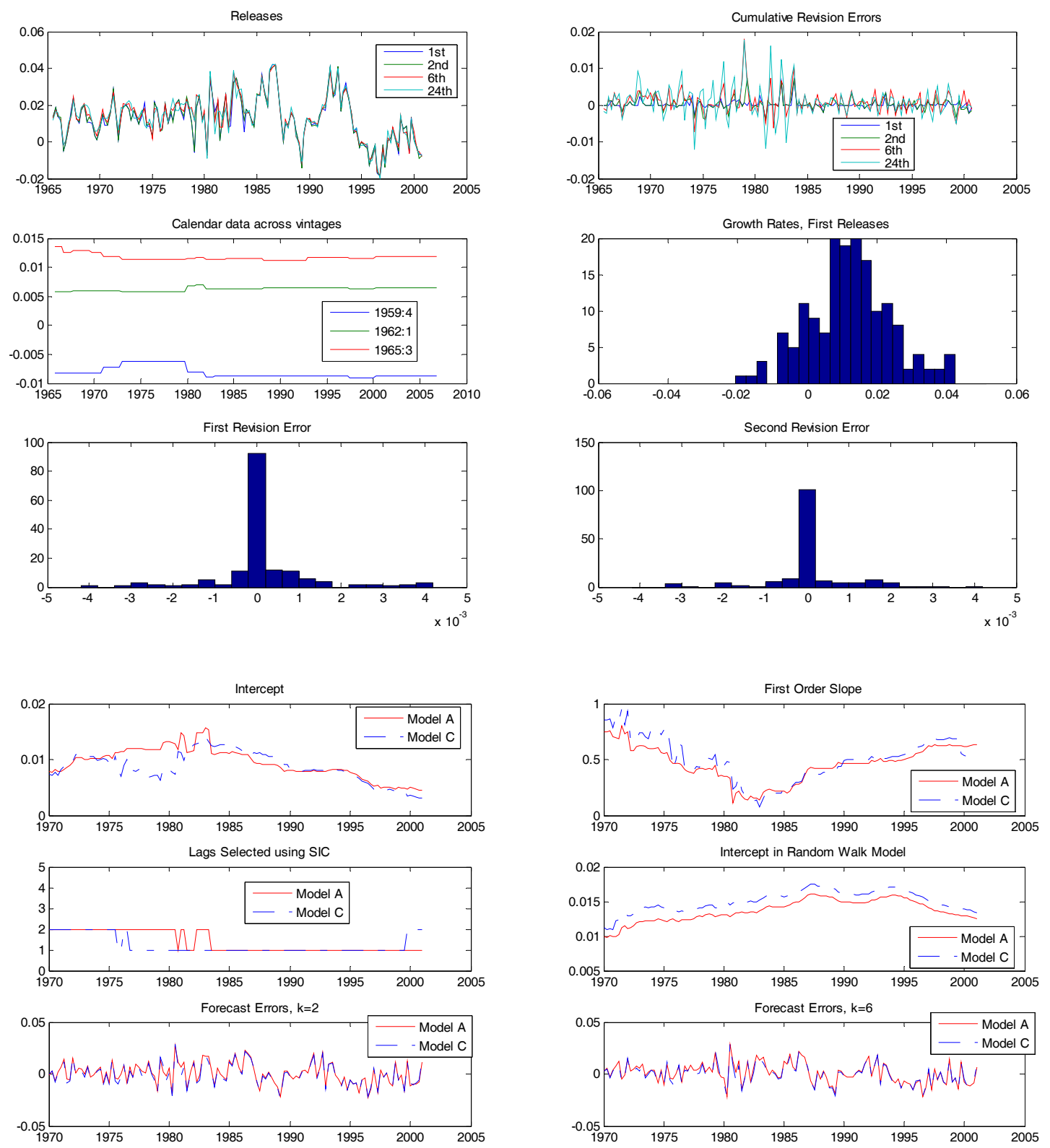

${ }^{(*)}$ Notes: See notes to Figure 1. 


\section{Appendix 1 - Forecast Experiment Results When Revision Errors Included}

Table A1.1: MSFEs Calculated Based on Simple Real-Time Autoregressions With Revision

Errors for Output ${ }^{(*)}$

\begin{tabular}{|c|c|c|c|c|c|c|c|}
\hline Model & RevErr & $k=2$ & $k=3$ & $k=4$ & $k=6$ & $k=12$ & $k=24$ \\
\hline \multicolumn{8}{|c|}{ Panel A: Mean Square Forecast Errors } \\
\hline \multicolumn{8}{|c|}{ Begin Date of Forecast Period $=1970: 1$} \\
\hline $\mathrm{A}$ & $u_{C 1}$ & 0.636 & 0.778 & 0.822 & 0.848 & 0.848 & 0.848 \\
\hline A & $u_{C 2}$ & 0.729 & 0.883 & 0.932 & 0.962 & 0.967 & 0.961 \\
\hline A & $u_{C 3}$ & 0.681 & 0.830 & 0.873 & 0.889 & 0.887 & 0.883 \\
\hline A & $u_{C 4}$ & 0.645 & 0.783 & 0.827 & 0.862 & 0.868 & 0.873 \\
\hline $\mathrm{C}$ & $u_{C 1}$ & 0.656 & 0.798 & 0.828 & 0.845 & 0.841 & 0.852 \\
\hline $\mathrm{C}$ & $u_{C 2}$ & 0.781 & 0.945 & 0.986 & 1.023 & 1.031 & 1.028 \\
\hline $\mathrm{C}$ & $u_{C 3}$ & $0.618^{*}$ & $0.749 *$ & $0.781 *$ & $0.827 *$ & $0.804^{*}$ & 0.818 \\
\hline $\mathrm{C}$ & $u_{C 4}$ & 0.659 & 0.811 & 0.846 & 0.886 & 0.892 & 0.902 \\
\hline \multicolumn{8}{|c|}{ Begin Date of Forecast Period $=1983: 1$} \\
\hline $\mathrm{A}$ & $u_{C 1}$ & 0.220 & 0.268 & 0.278 & 0.310 & 0.332 & 0.364 \\
\hline A & $u_{C 2}$ & 0.226 & 0.274 & 0.284 & 0.312 & 0.335 & 0.365 \\
\hline A & $u_{C 3}$ & 0.216 & 0.263 & 0.274 & 0.304 & 0.322 & 0.354 \\
\hline A & $u_{C 4}$ & 0.224 & 0.272 & 0.282 & 0.313 & 0.336 & 0.371 \\
\hline $\mathrm{C}$ & $u_{C 1}$ & 0.247 & 0.301 & 0.307 & 0.335 & 0.366 & 0.393 \\
\hline $\mathrm{C}$ & $u_{C 2}$ & 0.245 & 0.300 & 0.306 & 0.333 & 0.365 & 0.392 \\
\hline $\mathrm{C}$ & $u_{C 3}$ & 0.230 & 0.285 & 0.290 & 0.321 & 0.337 & 0.370 \\
\hline $\mathrm{C}$ & $u_{C 4}$ & 0.260 & 0.316 & 0.324 & 0.350 & 0.389 & 0.415 \\
\hline \multicolumn{8}{|c|}{ Begin Date of Forecast Period $=1990: 1$} \\
\hline A & $u_{C 1}$ & 0.184 & 0.211 & 0.222 & 0.286 & 0.295 & 0.342 \\
\hline A & $u_{C 2}$ & 0.186 & 0.212 & 0.224 & 0.288 & 0.297 & 0.343 \\
\hline A & $u_{C 3}$ & 0.176 & 0.205 & 0.217 & 0.279 & 0.288 & 0.332 \\
\hline A & $u_{C 4}$ & 0.185 & 0.213 & 0.224 & 0.288 & 0.300 & 0.351 \\
\hline $\mathrm{C}$ & $u_{C 1}$ & 0.206 & 0.238 & 0.241 & 0.306 & 0.324 & 0.366 \\
\hline $\mathrm{C}$ & $u_{C 2}$ & 0.201 & 0.233 & 0.237 & 0.303 & 0.321 & 0.365 \\
\hline $\mathrm{C}$ & $u_{C 3}$ & 0.193 & 0.227 & 0.231 & 0.293 & 0.302 & 0.348 \\
\hline $\mathrm{C}$ & $u_{C 4}$ & 0.215 & 0.246 & 0.250 & 0.321 & 0.340 & 0.383 \\
\hline \multicolumn{8}{|c|}{ 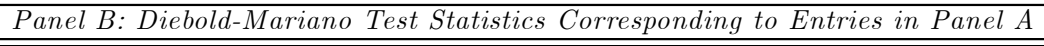 } \\
\hline \multicolumn{8}{|c|}{ Begin Date of Forecast Period $=1970: 1$} \\
\hline A & $u_{C 1}$ & 0.277 & 0.209 & 0.111 & -0.260 & -0.335 & -0.445 \\
\hline A & $u_{C 2}$ & -0.889 & -0.881 & -0.872 & -0.863 & -0.889 & -0.915 \\
\hline A & $u_{C 3}$ & -1.748 & -1.744 & -1.646 & -1.485 & -1.418 & -1.448 \\
\hline A & $u_{C 4}$ & -0.099 & -0.001 & -0.070 & -0.445 & -0.651 & -0.814 \\
\hline $\mathrm{C}$ & $u_{C 1}$ & -0.217 & -0.207 & -0.044 & -0.058 & -0.034 & -0.232 \\
\hline $\mathrm{C}$ & $u_{C 2}$ & -1.410 & -1.438 & -1.315 & -1.294 & -1.320 & -1.381 \\
\hline $\mathrm{C}$ & $u_{C 3}$ & 0.353 & 0.453 & 0.567 & 0.208 & 0.488 & 0.276 \\
\hline $\mathrm{C}$ & $u_{C 4}$ & -0.373 & -0.543 & -0.404 & -0.815 & -0.983 & -1.224 \\
\hline \multicolumn{8}{|c|}{ Begin Date of Forecast Period $=1983: 1$} \\
\hline A & $u_{C 1}$ & -1.084 & -0.958 & -0.884 & -0.742 & -1.118 & -0.978 \\
\hline A & $u_{C 2}$ & -1.539 & -1.404 & -1.308 & -0.853 & -1.154 & -1.022 \\
\hline A & $u_{C 3}$ & -1.309 & -1.304 & -1.277 & -0.302 & -0.104 & -0.111 \\
\hline A & $u_{C 4}$ & -1.180 & -1.045 & -0.974 & -0.851 & -1.151 & -1.253 \\
\hline $\mathrm{C}$ & $u_{C 1}$ & -1.284 & -1.369 & -1.200 & -1.058 & -1.362 & -1.154 \\
\hline $\mathrm{C}$ & $u_{C 2}$ & -1.248 & -1.342 & -1.167 & -1.018 & -1.369 & -1.174 \\
\hline $\mathrm{C}$ & $u_{C 3}$ & -0.954 & -1.267 & -0.996 & -0.891 & -0.704 & -0.688 \\
\hline $\mathrm{C}$ & $u_{C 4}$ & -1.448 & -1.544 & -1.469 & -1.214 & -1.594 & -1.430 \\
\hline \multicolumn{8}{|c|}{ Begin Date of Forecast Period $=1990: 1$} \\
\hline A & $u_{C 1}$ & -1.720 & -1.358 & -1.277 & -1.276 & -1.299 & -1.295 \\
\hline A & $u_{C 2}$ & -1.583 & -1.263 & -1.210 & -1.149 & -1.213 & -1.162 \\
\hline A & $u_{C 3}$ & -0.466 & -0.455 & -0.382 & -0.168 & -0.426 & -0.167 \\
\hline A & $u_{C 4}$ & -1.412 & -1.042 & -0.904 & -1.031 & -1.141 & -1.360 \\
\hline $\mathrm{C}$ & $u_{C 1}$ & -1.084 & -1.252 & -0.965 & -0.867 & -1.041 & -0.935 \\
\hline $\mathrm{C}$ & $u_{C 2}$ & -1.022 & -1.195 & -0.890 & -0.833 & -1.024 & -0.978 \\
\hline $\mathrm{C}$ & $u_{C 3}$ & -0.791 & -1.025 & -0.685 & -0.598 & -0.569 & -0.551 \\
\hline $\mathrm{C}$ & $u_{C 4}$ & -1.051 & -1.178 & -0.976 & -0.918 & -1.072 & -1.003 \\
\hline
\end{tabular}


(*) See notes to Table 3. Revision errors included as additional regressors in the prediction equations reported on in Table 3 are: $u_{C 1}={ }_{t+1} u_{t-1}^{t}, u_{C 2}=\left({ }_{t+1} u_{t-1}^{t},{ }_{t} u_{t-2}^{t-1}\right), u_{C 3}={ }_{t+1} u_{t-2}^{t-1}$, and $u_{C 4}=\left({ }_{t+1} u_{t-1}^{t},{ }_{t+1} u_{t-2}^{t}\right)$. Bold numbers highlight cases in which the inclusion of revision errors lowers the MSFE compared to models without revision errors (see Table 1-3). A star denotes cases in which a different model than the one found in Tables 3-5 reaches a lower MSFE. Further details are contained in Sections 3 and 4. 
Table A1.2: MSFEs Calculated Based on Simple Real-Time Autoregressions With Revision

\begin{tabular}{|c|c|c|c|c|c|c|c|}
\hline \multicolumn{8}{|c|}{ Errors for Prices ${ }^{(*)}$} \\
\hline Model & RevErr & $k=2$ & $k=3$ & $k=4$ & $k=6$ & $k=12$ & $k=24$ \\
\hline \multicolumn{8}{|c|}{ Panel A: Mean Square Forecast Errors } \\
\hline \multicolumn{8}{|c|}{ Begin Date of Forecast Period $=1970: 1$} \\
\hline $\mathrm{A}$ & $u_{C 1}$ & 0.145 & 0.163 & 0.164 & 0.161 & 0.136 & 0.124 \\
\hline $\mathrm{A}$ & $u_{C 2}$ & 0.143 & 0.161 & 0.162 & 0.160 & 0.136 & 0.121 \\
\hline A & $u_{C 3}$ & 0.153 & 0.170 & 0.170 & 0.167 & 0.141 & 0.124 \\
\hline A & $u_{C 4}$ & 0.150 & 0.166 & 0.167 & 0.166 & 0.139 & 0.122 \\
\hline $\mathrm{C}$ & $u_{C 1}$ & 0.155 & 0.174 & 0.177 & 0.173 & 0.146 & 0.132 \\
\hline $\mathrm{C}$ & $u_{C 2}$ & 0.164 & 0.183 & 0.187 & 0.185 & 0.155 & 0.137 \\
\hline $\mathrm{C}$ & $u_{C 3}$ & 0.159 & 0.178 & 0.181 & 0.178 & 0.150 & 0.136 \\
\hline $\mathrm{C}$ & $u_{C 4}$ & 0.156 & 0.174 & 0.177 & 0.175 & 0.148 & 0.133 \\
\hline \multicolumn{8}{|c|}{ Begin Date of Forecast Period =1983:1 } \\
\hline $\mathrm{A}$ & $u_{C 1}$ & 0.072 & 0.076 & 0.075 & 0.069 & 0.063 & 0.063 \\
\hline A & $u_{C 2}$ & 0.070 & 0.073 & 0.073 & 0.069 & 0.064 & 0.061 \\
\hline A & $u_{C 3}$ & 0.072 & 0.076 & 0.076 & 0.070 & 0.064 & 0.064 \\
\hline A & $u_{C 4}$ & 0.073 & 0.076 & 0.076 & 0.071 & 0.062 & 0.060 \\
\hline $\mathrm{C}$ & $u_{C 1}$ & 0.076 & 0.081 & 0.081 & 0.076 & 0.069 & 0.068 \\
\hline $\mathrm{C}$ & $u_{C 2}$ & 0.077 & 0.081 & 0.082 & 0.080 & 0.074 & 0.069 \\
\hline $\mathrm{C}$ & $u_{C 3}$ & 0.080 & 0.084 & 0.083 & 0.079 & 0.071 & 0.069 \\
\hline $\mathrm{C}$ & $u_{C 4}$ & 0.078 & 0.082 & 0.081 & 0.077 & 0.070 & 0.067 \\
\hline \multicolumn{8}{|c|}{ Begin Date of Forecast Period =1990:1 } \\
\hline $\bar{A}$ & $u_{C 1}$ & 0.057 & 0.046 & 0.050 & 0.049 & 0.041 & 0.042 \\
\hline A & $u_{C 2}$ & 0.053 & 0.043 & 0.048 & 0.048 & 0.042 & 0.043 \\
\hline A & $u_{C 3}$ & 0.058 & 0.047 & 0.051 & 0.050 & 0.041 & 0.043 \\
\hline A & $u_{C 4}$ & 0.057 & 0.045 & 0.050 & 0.049 & 0.041 & 0.044 \\
\hline $\mathrm{C}$ & $u_{C 1}$ & 0.063 & 0.053 & 0.055 & 0.055 & 0.045 & 0.045 \\
\hline C & $u_{C 2}$ & 0.060 & 0.050 & 0.056 & 0.056 & 0.048 & 0.048 \\
\hline $\mathrm{C}$ & $u_{C 3}$ & 0.066 & 0.055 & 0.057 & 0.057 & 0.046 & 0.046 \\
\hline $\mathrm{C}$ & $u_{C 4}$ & 0.065 & 0.054 & 0.056 & 0.057 & 0.046 & 0.047 \\
\hline \multicolumn{8}{|c|}{ Panel B: Diebold-Mariano Test Statistics Corresponding to Entries in Panel A } \\
\hline \multicolumn{8}{|c|}{ Begin Date of Forecast Period =1970:1 } \\
\hline $\mathrm{A}$ & $u_{C 1}$ & 0.397 & 0.284 & 0.247 & 0.185 & 0.347 & 0.110 \\
\hline A & $u_{C 2}$ & 0.592 & 0.567 & 0.478 & 0.279 & 0.378 & 0.486 \\
\hline A & $u_{C 3}$ & -1.086 & -0.862 & -0.846 & -0.902 & -0.472 & 0.132 \\
\hline A & $u_{C 4}$ & -0.127 & 0.033 & -0.033 & -0.241 & 0.087 & 0.292 \\
\hline $\mathrm{C}$ & $u_{C 1}$ & -0.480 & -0.619 & -0.702 & -0.765 & -0.618 & -0.621 \\
\hline $\mathrm{C}$ & $u_{C 2}$ & -1.074 & -1.141 & -1.234 & -1.387 & -1.260 & -0.904 \\
\hline $\mathrm{C}$ & $u_{C 3}$ & -0.792 & -0.930 & -0.961 & -1.076 & -1.007 & -0.908 \\
\hline $\mathrm{C}$ & $u_{C 4}$ & -0.563 & -0.670 & -0.756 & -0.857 & -0.732 & -0.676 \\
\hline \multicolumn{8}{|c|}{ Begin Date of Forecast Period $=1983: 1$} \\
\hline $\mathrm{A}$ & $u_{C 1}$ & 0.070 & 0.455 & 0.317 & 0.219 & 0.064 & 0.653 \\
\hline A & $u_{C 2}$ & 0.665 & 0.957 & 0.741 & 0.213 & -0.427 & 0.822 \\
\hline A & $u_{C 3}$ & -0.440 & -1.109 & -1.249 & -1.680 & -1.528 & -1.568 \\
\hline A & $u_{C 4}$ & -0.217 & 0.131 & -0.020 & -0.325 & 0.292 & 0.599 \\
\hline $\mathrm{C}$ & $u_{C 1}$ & -1.151 & -1.301 & -1.242 & -1.610 & -1.337 & -0.976 \\
\hline $\mathrm{C}$ & $u_{C 2}$ & -1.062 & -0.878 & -1.454 & -2.333 & -2.420 & -1.502 \\
\hline $\mathrm{C}$ & $u_{C 3}$ & -1.914 & -1.866 & -1.730 & -2.235 & -1.705 & -1.158 \\
\hline $\mathrm{C}$ & $u_{C 4}$ & -1.474 & -1.400 & -1.355 & -1.677 & -1.529 & -0.936 \\
\hline \multicolumn{8}{|c|}{ Begin Date of Forecast Period $=1990: 1$} \\
\hline $\mathrm{A}$ & $u_{C 1}$ & 0.614 & 0.445 & 0.569 & 0.370 & -0.176 & 1.601 \\
\hline A & $u_{C 2}$ & 0.836 & 0.861 & 0.723 & 0.241 & -0.414 & -0.007 \\
\hline A & $u_{C 3}$ & -0.613 & -0.991 & -1.176 & -1.751 & -1.665 & -1.380 \\
\hline A & $u_{C 4}$ & 0.156 & 0.367 & 0.221 & -0.109 & -0.206 & -0.339 \\
\hline $\mathrm{C}$ & $u_{C 1}$ & -1.316 & -1.496 & -0.902 & -1.107 & -0.794 & -0.561 \\
\hline $\mathrm{C}$ & $u_{C 2}$ & -0.600 & -0.640 & -1.257 & -1.503 & -2.111 & -1.646 \\
\hline $\mathrm{C}$ & $u_{C 3}$ & -1.856 & -1.951 & -1.279 & -1.341 & -0.962 & -0.672 \\
\hline $\mathrm{C}$ & $u_{C 4}$ & -1.656 & -1.768 & -1.186 & -1.409 & -1.091 & -0.870 \\
\hline
\end{tabular}

(*) See notes to Table 3 and Table A1.1. 
Table A1.3: MSFEs Calculated Based on Simple Real-Time Autoregressions With Revision

Errors for Money ${ }^{(*)}$

\begin{tabular}{|c|c|c|c|c|c|c|c|}
\hline Model & RevErr & $k=2$ & $k=3$ & $k=4$ & $k=6$ & $k=12$ & $k=24$ \\
\hline \multicolumn{8}{|c|}{ Panel A: Mean Square Forecast Errors } \\
\hline \multicolumn{8}{|c|}{ Begin Date of Forecast Period =1970:1 } \\
\hline $\bar{A}$ & $u_{C 1}$ & 1.035 & 1.030 & 1.013 & 0.937 & 0.982 & 0.992 \\
\hline A & $u_{C 2}$ & 1.030 & 1.026 & 1.012 & 0.934 & 0.979 & 0.992 \\
\hline A & $u_{C 3}$ & 1.030 & 1.024 & 1.008 & 0.935 & 0.983 & 1.001 \\
\hline A & $u_{C 4}$ & 1.043 & 1.038 & 1.020 & 0.944 & 0.988 & 1.001 \\
\hline $\mathrm{C}$ & $u_{C 1}$ & 1.037 & 1.029 & 1.014 & 0.935 & 0.961 & 0.979 \\
\hline $\mathrm{C}$ & $u_{C 2}$ & 1.044 & 1.036 & 1.023 & 0.942 & 0.969 & 0.991 \\
\hline $\mathrm{C}$ & $u_{C 3}$ & 1.040 & 1.030 & 1.012 & 0.933 & 0.963 & 0.983 \\
\hline $\mathrm{C}$ & $u_{C 4}$ & 1.075 & 1.067 & 1.050 & 0.968 & 0.992 & 1.001 \\
\hline \multicolumn{8}{|c|}{ Begin Date of Forecast Period $=1983: 1$} \\
\hline $\mathrm{A}$ & $u_{C 1}$ & 1.161 & 1.135 & 1.093 & 0.992 & 1.010 & 1.033 \\
\hline A & $u_{C 2}$ & 1.147 & 1.121 & 1.080 & 0.984 & 1.002 & 1.031 \\
\hline A & $u_{C 3}$ & 1.157 & 1.130 & 1.089 & 0.998 & 1.011 & 1.036 \\
\hline $\mathrm{A}$ & $u_{C 4}$ & 1.163 & 1.137 & 1.095 & 0.994 & 1.012 & 1.035 \\
\hline $\mathrm{C}$ & $u_{C 1}$ & 1.117 & 1.089 & 1.043 & 0.948 & 0.958 & 0.984 \\
\hline $\mathrm{C}$ & $u_{C 2}$ & 1.112 & 1.084 & 1.039 & 0.947 & 0.956 & 0.987 \\
\hline $\mathrm{C}$ & $u_{C 3}$ & 1.119 & 1.089 & 1.042 & 0.950 & 0.960 & 0.985 \\
\hline $\mathrm{C}$ & $u_{C 4}$ & 1.121 & 1.093 & 1.046 & 0.951 & 0.960 & 0.987 \\
\hline \multicolumn{8}{|c|}{ Begin Date of Forecast Period $=1990: 1$} \\
\hline $\bar{A}$ & $u_{C 1}$ & 1.064 & 1.065 & 1.042 & 0.905 & 0.897 & 0.950 \\
\hline A & $u_{C 2}$ & 1.051 & 1.051 & 1.028 & 0.892 & 0.884 & 0.937 \\
\hline A & $u_{C 3}$ & 1.050 & 1.049 & 1.025 & 0.907 & 0.896 & 0.948 \\
\hline A & $u_{C 4}$ & 1.068 & 1.069 & 1.046 & 0.907 & 0.900 & 0.953 \\
\hline $\mathrm{C}$ & $u_{C 1}$ & 1.028 & 1.028 & 1.002 & 0.875 & 0.861 & 0.916 \\
\hline $\mathrm{C}$ & $u_{C 2}$ & 1.021 & 1.020 & 0.996 & 0.870 & 0.857 & 0.911 \\
\hline $\mathrm{C}$ & $u_{C 3}$ & 1.028 & 1.025 & 0.997 & 0.877 & 0.864 & 0.918 \\
\hline $\mathrm{C}$ & $u_{C 4}$ & 1.031 & 1.031 & 1.005 & 0.877 & 0.862 & 0.918 \\
\hline \multicolumn{8}{|c|}{ Panel B: Diebold-Mariano Test Statistics Corresponding to Entries in Panel A } \\
\hline \multicolumn{8}{|c|}{ Begin Date of Forecast Period $=1970: 1$} \\
\hline $\mathrm{A}$ & $u_{C 1}$ & -0.282 & -0.344 & -0.287 & 0.033 & 0.165 & 0.413 \\
\hline A & $u_{C 2}$ & -0.028 & -0.075 & -0.121 & 0.122 & 0.192 & 0.254 \\
\hline A & $u_{C 3}$ & -0.031 & -0.003 & 0.030 & 0.227 & 0.100 & -0.272 \\
\hline A & $u_{C 4}$ & -0.613 & -0.615 & -0.533 & -0.318 & -0.242 & -0.162 \\
\hline $\mathrm{C}$ & $u_{C 1}$ & -0.221 & -0.171 & -0.183 & 0.085 & 0.728 & 0.597 \\
\hline $\mathrm{C}$ & $u_{C 2}$ & -0.334 & -0.300 & -0.370 & -0.119 & 0.387 & 0.174 \\
\hline $\mathrm{C}$ & $u_{C 3}$ & -0.325 & -0.207 & -0.133 & 0.140 & 0.689 & 0.461 \\
\hline $\mathrm{C}$ & $u_{C 4}$ & -1.051 & -1.016 & -0.972 & -0.785 & -0.194 & -0.075 \\
\hline \multicolumn{8}{|c|}{ Begin Date of Forecast Period $=1983: 1$} \\
\hline $\mathrm{A}$ & $u_{C 1}$ & 0.245 & 0.197 & 0.224 & 0.685 & 0.553 & 0.339 \\
\hline A & $u_{C 2}$ & 0.441 & 0.410 & 0.408 & 0.562 & 0.471 & 0.231 \\
\hline A & $u_{C 3}$ & 0.506 & 0.510 & 0.510 & 0.441 & 0.500 & 0.211 \\
\hline A & $u_{C 4}$ & 0.169 & 0.123 & 0.145 & 0.610 & 0.462 & 0.256 \\
\hline $\mathrm{C}$ & $u_{C 1}$ & 1.199 & 1.214 & 1.350 & 1.636 & 1.695 & 1.527 \\
\hline $\mathrm{C}$ & $u_{C 2}$ & 1.035 & 1.046 & 1.137 & 1.284 & 1.308 & 1.154 \\
\hline $\mathrm{C}$ & $u_{C 3}$ & 1.303 & 1.384 & 1.552 & 1.656 & 1.728 & 1.603 \\
\hline $\mathrm{C}$ & $u_{C 4}$ & 1.106 & 1.121 & 1.258 & 1.548 & 1.627 & 1.441 \\
\hline \multicolumn{8}{|c|}{ Begin Date of Forecast Period =1990:1 } \\
\hline $\mathrm{A}$ & $u_{C 1}$ & -0.162 & -0.188 & -0.183 & 0.357 & 0.325 & 0.150 \\
\hline A & $u_{C 2}$ & 0.185 & 0.175 & 0.162 & 0.758 & 0.703 & 0.523 \\
\hline A & $u_{C 3}$ & 0.649 & 0.699 & 0.714 & 0.786 & 0.821 & 0.556 \\
\hline A & $u_{C 4}$ & -0.255 & -0.280 & -0.279 & 0.262 & 0.219 & 0.060 \\
\hline $\mathrm{C}$ & $u_{C 1}$ & 0.767 & 0.743 & 0.801 & 1.353 & 1.429 & 1.111 \\
\hline $\mathrm{C}$ & $u_{C 2}$ & 0.987 & 0.982 & 1.001 & 1.574 & 1.577 & 1.292 \\
\hline $\mathrm{C}$ & $u_{C 3}$ & 0.946 & 1.032 & 1.158 & 1.328 & 1.424 & 1.199 \\
\hline $\mathrm{C}$ & $u_{C 4}$ & 0.674 & 0.649 & 0.714 & 1.245 & 1.337 & 1.020 \\
\hline
\end{tabular}

(*) See notes to Table 3 and Table A1.1. 